Santa Clara University

Scholar Commons

Economics

Leavey School of Business

$8-22-2017$

\title{
Local neighbors as positives, regional neighbors as negatives: Competing channels in the relationship between others income, health, and happiness
}

John Ifcher

Santa Clara University, jifcher@scu.edu

Homa Zarghamee

Carol Graham

Follow this and additional works at: https://scholarcommons.scu.edu/econ

Part of the Economics Commons

\section{Recommended Citation}

Ifcher, J., Zarghamee, H., \& Graham, C. (2018). Local neighbors as positives, regional neighbors as negatives: Competing channels in the relationship between others' income, health, and happiness. Journal of Health Economics, 57, 263-276. https://doi.org/10.1016/ j.jhealeco.2017.08.003.

(C) 2017 Elsevier B.V. This manuscript version is made available under the CC-BY-NC-ND 4.0 license http://creativecommons.org/licenses/by-nc-nd/ $4.0 \%$.

This Article is brought to you for free and open access by the Leavey School of Business at Scholar Commons. It has been accepted for inclusion in Economics by an authorized administrator of Scholar Commons. For more information, please contact rscroggin@scu.edu. 
IZA DP No. 9934

Local Neighbors as Positives, Regional Neighbors as Negatives: Competing Channels in the Relationship between Others' Income, Health, and Happiness

John Ifcher

Homa Zarghamee

Carol Graham

May 2016 


\title{
Local Neighbors as Positives, Regional Neighbors as Negatives: Competing Channels in the Relationship between Others' Income, Health, and Happiness
}

\author{
John Ifcher \\ Santa Clara University and IZA \\ Homa Zarghamee \\ Barnard College, Columbia University \\ Carol Graham \\ Brookings Institution, \\ University of Maryland and IZA \\ Discussion Paper No. 9934 \\ May 2016 \\ IZA \\ P.O. Box 7240 \\ 53072 Bonn \\ Germany \\ Phone: +49-228-3894-0 \\ Fax: +49-228-3894-180 \\ E-mail: iza@iza.org
}

\begin{abstract}
Any opinions expressed here are those of the author(s) and not those of IZA. Research published in this series may include views on policy, but the institute itself takes no institutional policy positions. The IZA research network is committed to the IZA Guiding Principles of Research Integrity.

The Institute for the Study of Labor (IZA) in Bonn is a local and virtual international research center and a place of communication between science, politics and business. IZA is an independent nonprofit organization supported by Deutsche Post Foundation. The center is associated with the University of Bonn and offers a stimulating research environment through its international network, workshops and conferences, data service, project support, research visits and doctoral program. IZA engages in (i) original and internationally competitive research in all fields of labor economics, (ii) development of policy concepts, and (iii) dissemination of research results and concepts to the interested public.
\end{abstract}

IZA Discussion Papers often represent preliminary work and are circulated to encourage discussion. Citation of such a paper should account for its provisional character. A revised version may be available directly from the author. 


\title{
ABSTRACT
}

\section{Local Neighbors as Positives, Regional Neighbors as Negatives: Competing Channels in the Relationship between Others' Income, Health, and Happiness ${ }^{*}$}

\begin{abstract}
We develop a theoretical framework that integrates four distinct channels through which others' income can affect utility: public goods, cost of living, expectations of future income, and direct effects (relative income hypothesis and/or altruism). We empirically estimate the relationship with U.S. well-being and health data from Gallup and geographically-based median-income data for ZIP codes and MSAs. The relationship is proximity-dependent: positive (negative) with ZIP-code (MSA) median income as reference income, suggesting that positive (negative) channels dominate locally (regionally) and reconciling seemingly divergent results from the literature. Additional analyses provide evidence of the importance of the public-goods and cost-of-living channels.
\end{abstract}

JEL Classification: D6, D31, I31

Keywords: subjective well-being, relative income hypothesis, others' income, reference group, relative utility, income comparison, happiness

Corresponding author:

Homa Zarghamee

Barnard College

Columbia University

3009 Broadway

New York, NY 10027

USA

E-mail: hzargham@barnard.edu

\footnotetext{
* The authors thank seminar participants at Santa Clara University, FGV-Rio de Janiero, and the 2015 Western Economics Association International conference. Ifcher graciously acknowledges financial support from a Leavey Research Grant from Santa Clara University.
} 


\section{Introduction}

That well-being is decreasing in others' income has been termed the "relative income hypothesis" (RIH) by scholars of subjective well-being (SWB) and has substantial empirical support (e.g., Blanchflower \& Oswald, 2004; Clark et al., 2008; Helliwell et al., 2012; Luttmer, 2005). A handful of studies, however, present evidence that the relationship between others' income and well-being is complex, with multiple explanatory channels (positive and negative) at play concurrently (e.g., Brodeur \& Fleche, 2015; Clark et al., 2009a; Deaton \& Stone, 2013; Kingdon \& Knight, 2007; Senik, 2008).

To systematically examine the relationship between others' income and well-being, we restrict our attention to geographically based reference groups (i.e., neighbors, the most prevalent benchmark in the literature) and develop a unified theoretical framework that considers four distinct explanatory channels through which neighbors' income might affect utility: public goods, cost of living, expectations of future income, and direct effects (RIH and altruism). We show that the relationship is theoretically ambiguous and then empirically estimate it. To proxy for utility, we use a wide range of SWB measures from the U.S. Gallup-Healthways Well-Being Index (GHWBI) survey; ${ }^{1}$ and to proxy for neighbors' income, we use geographically-based median-income data from the American Community Survey (ACS). We use two distinct geographic areas-ZIP code and Metropolitan Statistical Area (MSA) - to explore whether our explanatory channels vary with reference-group proximity. ${ }^{2}$

\footnotetext{
${ }^{1}$ Recent research finds that while SWB cannot be considered a proxy for utility, insofar as people do not exclusively make choices to maximize it, it can be considered a "uniquely important argument of the utility function" (Benjamin et al., 2012) (see also Angner (2010) and Benjamin et al. (2014)). The outcome variable in our theoretical framework is utility, and we use SWB as a proxy for it in the empirical analysis, recognizing its shortcomings as such.

2 ZIP-codes are postal designations with an average population of roughly 7,500 individuals. MSAs designate larger, more populated areas with an average population of roughly 850,000 individuals. Specifically, the Census defines the MSA as "a large population nucleus [with a minimum of 50,000 individuals], together with adjacent communities having a high degree of social and economic integration with that core. Metropolitan areas comprise one or more entire counties, except in New England, where cities and towns are the basic geographic units." (http://quickfacts.census.gov/qfd/meta/long_metro.htm)
} 
We find that the sign of the relationship between SWB and neighbors' income is proximity-dependent: the relationship is positive when using ZIP-code median income as the reference income and negative when using MSA. This suggests that positive channels dominate locally while negative channels dominate regionally, demonstrating that the RIH is not always the dominant channel by which others' income and well-being are related. These findings are consistent across SWB measures and a wide range of healthrelated indices, for a variety of specification checks, and for most subgroups. One important exception is that, for the subgroup of low-income individuals living in lowincome ZIP-codes, negative channels dominate locally and positive channels dominate regionally. Lastly, conditioning on explanatory-channel proxies, we find that the relationship between SWB and neighbors' income is either nullified or rendered positive, suggesting that the RIH is either inoperant or offset by altruism. Of the other channels, the public-goods channel is operant at the ZIP-code- and MSA-levels, whereas the costof-living channel is operant at the MSA-level.

Our research contributes to the literature by providing a unified theoretical framework of the relationship between neighbors' income and utility. Our approach is subtly different from much of the literature in that we holistically consider the possible ways in which utility may be impacted by neighbors' income. As such, our model and estimation organize the multiple channels through which the relationship may be mediated to give equal prominence to non-relative-income channels (i.e., public goods, cost of living, and altruism) as to relative-income channels (i.e., RIH and expectations of future income). Another contribution is that our empirical analyses use a large, nationally representative U.S. sample from a dataset uniquely rich in measures of well-being, with six SWB indices that can meaningfully attempt to proxy for utility and twelve healthrelated indices. In addition to addressing robustness, having multiple SWB measures in the same dataset is important due to the nuances of different types of SWB and to examine whether they respond differently to SWB-determinants. 


\section{Literature review}

Interest in the theoretical relationship between others' income and well-being has a long tradition in economics dating back at least as far as Veblen (1899). Duesenberry (1949) puts forth the RIH, asserting that individual consumption behavior is influenced by one's income relative to a reference group or one's past consumption. Duesenberry's RIH was revived by Frank (1985) and, in the SWB literature, has come to mean that income comparisons cause SWB to decrease with others' income. It has been used as a potential explanation for the Easterlin Paradox - whereby, over time at the national level, average SWB does not increase with per capita GDP (Easterlin, 1974; Frank, 2012). ${ }^{3,4}$

The relationship between others' income and SWB has been studied using different benchmarks for reference income: geography (e.g., Brodeur \& Fleche, 2015; Clark et al., 2009a; Clark \& Senik, 2012; Deaton \& Stone, 2013; Luttmer, 2005); occupation (e.g., Senik, 2004; 2008); demographic characteristics like age, sex, race, and religion (e.g., Dahlin et al., 2014; FitzRoy et al., 2014; Perez-Asenjo, 2011); education (e.g., Graham \& Felton, 2006); friends and family (e.g., Senik, 2009); one's own past (e.g., Knight et al., 2009; Senik, 2009); and combinations thereof (e.g., Ferrer-i-Carbonell, 2005; McBride, 2010).

In the current paper, "others" are defined based on geographic proximity, the most prevalent benchmark used in the literature; we henceforth refer to "neighbors" to mean geographically proximate others. We use geographic reference groups because they are the most frequently used in the literature, not because we consider geographic reference groups to be more impactful or important than other reference groups. Our theoretical

\footnotetext{
${ }^{3}$ In sociology, the RIH is conceptualized as the contrapositive--feelings of relative deprivation arising from unfavorable personal comparisons to others (e.g., Davis, 1959).

${ }^{4}$ Concerns about the validity and reliability of SWB metrics have been addressed at length elsewhere, and we refer interested readers to the corresponding literature. SWB metrics have been shown to be psychometrically sound, internally consistent and comparable across individuals, over time, and for different levels of economic development (Diener et al., 1999; Helliwell et al., 2010; Krueger \& Schkade, 2008). Further, they are increasingly used in public policy and economic analyses (Diener et al., 2009; Di Tella \& MacCulloch, 2006; O'Donnell, 2013; Stiglitz et al., 2010; Stone \& Mackie, 2013). Indeed, some countries (e.g., Bhutan, Britain, and France) are now including SWB metrics in official statistics.
} 
framework considers channels that mediate utility and neighbors' income. Channels mediating utility and the income of other reference groups would presumably differ. For example, the cost-of-living channel may be less relevant if considering occupational reference groups. Our identification strategy uses multiple levels of geographic proximity to assess the dominance of the various explanatory channels — of which the RIH is but one. As such, we organize the literature review around these channels.

\subsection{Direct effect (RIH and altruism)}

Perhaps the best known empirical support of the RIH is Luttmer (2005), which uses Public Use Microdata Area (PUMA) median income as reference income. ${ }^{5}$ Luttmer $^{2}$ reports a negative relationship between individuals' PUMA median income and SWB that is of the same magnitude as the positive relationship between own income and SWB. Because controls are included for PUMA-level housing prices (as a proxy for cost of living), the result is interpreted as supportive of the RIH. Two authoritative literature reviews reach the same conclusion (Clark et al., 2008; Helliwell et al., 2012). Daly \& Using the U.S. General Social Survey, Wilson (2009) find that the perception that own income is lower than the typical U.S. family's increases the risk of suicide.

In contrast, Kingdon \& Knight (2007) find a positive relationship between neighbors' income and SWB using data from South Africa, with the magnitude of the neighbors' income coefficient exceeding own income's. Like Luttmer (2005), the reference group is geographic, but South African "clusters" are much smaller than PUMAs, containing roughly 3,000 individuals. The authors test various explanations for the relationship and rule out that it is driven by mutual insurance, observable public goods, or measurement error. The preferred interpretation is community-level altruism, as the positive relationship becomes negative and insignificant as the reference groups become larger and less geographically proximate. The authors also note that unobserved public goods cannot be ruled out as an interpretation.

\footnotetext{
${ }^{5}$ PUMAs are geographic areas used for Census surveying and have an average (minimum) of 150,000 $(100,000)$ people.
} 


\subsection{Cost of living}

Another channel by which neighbors' income can impact SWB is through cost of living. Neighbors with high income might be indicative of a higher cost of living, reducing real income and SWB. Luttmer (2005) attempts to account for cost of living in the relationship between neighbors' income and SWB by controlling for local housing prices, and finds that local housing prices are negatively correlated to SWB. Similarly, Glaeser et al. (2016) find a negative relationship between median housing prices and SWB. Lastly, the negative relationship between the inflation rate and SWB identified in the literature suggests SWB decreases with cost of living (Di Tella et al., 2001).

\subsection{Expectations of future income (tunnel effect and zero-sum effect)}

Hirschman \& Rothschild (1973) put forward another theoretical relationship between others' income and SWB called the "tunnel effect," whereby others' income can serve as a positive signal of one's future income and enhance current utility. Hirschman \& Rothschild's model focuses on early periods of rapid economic development; they posit that the tunnel effect is likely short-lived, as individuals' expectations become disappointments if not realized. The model was reinstituted in the SWB literature by Senik $(2004 ; 2008)$; using predicted occupation-income as the reference income, Senik $(2004 ; 2008)$ finds evidence consistent with the tunnel effect in "new" Europe (transition economies) and the U.S.: controlling for own income, there is a positive relationship between SWB and reference income. In "old" Europe, on the other hand, the relationship is negative. While evidence consistent with the tunnel effect in the SWB literature has also been reported by Clark et al. (2009b), D’Ambrosio \& Frick (2012) and FitzRoy et al. (2014), it should be noted that none of this evidence emerges using static geographicallybased reference groups. Hirschman \& Rothschild (1973) also note that it is possible for others' income to serve as a negative signal of one's future income. While this effect is not named and receives less attention, the example provided is one of a resourceconstrained society that members perceive as a zero-sum game. We will refer to this as the "zero-sum effect." 


\subsection{Public goods}

Deaton \& Stone (2013) use the U.S. GHWBI to examine the relationship between neighbors' income and both evaluative and hedonic SWB, ${ }^{6}$ using various geographic reference groups ranging from ZIP codes $(\sim 7,500$ individuals, on average) to states $(\sim 6.4$ million individuals, on average). First they estimate standard individual-level SWB equations to obtain an own-income coefficient. They then aggregate observations at various geographic levels to estimate an SWB equation for each level of aggregation (e.g., ZIP code, state, etc.). They reason that if the RIH is the dominant channel in the relationship between neighbors' income and SWB, then the relationship between, for example, ZIP-code average income and ZIP-code average SWB should be smaller than the own-income coefficient in the individual-level SWB regression. They find that the relationship between average income and evaluative SWB in the ZIP-code level regression exceeds the own-income coefficient in the individual-level regression. The authors speculate that this may be driven by public goods and/or expectations of future income (specifically, permanent income may impact evaluative SWB, and ZIP-code income may better proxy for permanent income than does own current income). However, in line with the RIH, the average-income coefficient decreases in magnitude with increased aggregation thereafter. That said, the largest decrease in magnitude compared to the individual-level regression is fairly small ( $20 \%$ decline).

In contrast, Deaton \& Stone find more support for the RIH using hedonic SWB, as measured by happiness felt yesterday. Unlike evaluative SWB, the average-income coefficient in the ZIP-code level regression is smaller than the own-income coefficient in the individual-level regression. As with evaluative SWB, the average income coefficient

\footnotetext{
${ }^{6}$ There is increasing consensus among scholars on the need to differentiate two distinct measurable dimensions of well-being: evaluative and hedonic. Evaluative well-being captures how people assess their lives or particular domains of their lives; it is typically measured on numerical scales corresponding to life satisfaction or happiness. Hedonic well-being captures the quality of individuals' experiences in their daily lives and their moods during those experiences; it is typically measured on a numerical scale corresponding to positive and/or negative affect during a relatively short time frame. It should be noted that there is a third dimension that has recently emerged as a distinct category: eudemonic well-being assesses the extent to which individuals have purpose or meaning in their lives. For a detailed discussion of the distinct dimensions of SWB metrics and the corresponding report for the National Academy of Sciences, see Stone and Mackie (2013).
} 
decreases in magnitude with increased aggregation, but the decreases are greater in magnitude: at the state level, average income and hedonic SWB are insignificantly correlated, suggesting that the magnitude of the negative relationship between hedonic SWB and state average income fully offsets the positive relationship between hedonic SWB and own-income. The authors speculate that hedonic SWB may be more relational than evaluative SWB, or that it is more responsive to transitory than permanent income, with transitory-income effects being washed out with increased aggregation.

Brodeur \& Fleche (2015) use the Centers for Disease Control and Prevention's Behavioral Risk Factor Surveillance System to estimate the relationship between neighbors' income and life satisfaction at the ZIP-code and county levels in eight U.S. states (Arizona, Maine, Ohio, Rhode Island, South Dakota, Texas, Utah and Wyoming). Controlling for housing prices, they obtain positive ZIP-code and negative county median-income coefficients. When they control for ZIP-code and county-level public goods (e.g., number of schools, health expenditure, murder rate) and economic conditions (poverty rate, unemployment rate), the positive ZIP-code median-income coefficient reduces in magnitude and becomes statistically insignificant, and the negative county median-income coefficient increases in magnitude. They interpret these results as supporting the importance of public goods in mediating the relationship between neighbors' income and SWB. They use a small dataset from Somerville, MA that allows them to examine the relationship between neighbors' income and SWB for more proximate levels of geographic aggregation. There, the results flip: the street/block median-income coefficient is negative, while the precinct median-income coefficient is positive. They interpret these results as supporting the RIH, and speculate that the RIH is strongest at this level because the consumption of immediate neighbors is directly observable.

Lastly, using Danish panel data, Clark et al. (2009a) find that economic satisfaction significantly increases with neighborhood median income ( $\sim 600$ households) but is unrelated to municipality median-income. Including a control for one's rank in the neighborhood income distribution increases the magnitude of the positive relationship 
between economic satisfaction and neighborhood median income but significantly diminishes the positive relationship between economic satisfaction and own income. The authors speculate that the positive relationship between economic satisfaction and neighborhood median income is mediated by public goods.

\section{Theoretical framework: channels connecting neighbors' income and utility}

We develop a theoretical framework that illustrates the channels through which neighbors' income affects utility; the model will provide the basis for interpreting the empirical results. The model integrates four distinct channels that have not yet been considered together in the literature: public goods, cost of living, expectations of future income, and direct effects (see Figure 1). The first channel includes public goods, such as, parks, public safety, schools, and utility-spillovers; the second channel accounts for the cost of living; the third channel captures the signaling effect of neighbors' income on expectations of future income; and the fourth channel captures the effects of RIH and/or altruism. The sign of each relationship is illustrated in Figure 1 as positive, negative, or ambiguous. $^{7}$

Based on the framework, and building on Hirschman \& Rothschild (1973) and Senik (2008), the utility function can be expressed as follows:

$$
U^{A}=V\left[Y^{A}, P G^{A}\left(Y^{B}\right), C L^{A}\left(Y^{B}\right), E^{A}\left(Y^{B}\right), Y^{B}\right]
$$

where individual A's indirect utility function depends on her income, $Y^{A}$; the level of public goods to which A is exposed, $P G^{A}$; cost of living, $C L^{A}$; expectations of future income, $E^{A}$; and individual B's income, $Y^{B} . P G^{A}, C L^{A}, \& E^{A}$ are all functions of $Y^{B}$.

\footnotetext{
${ }^{7}$ Utility spillovers refer to SWB-improvements that result from the increased SWB of neighbors, while altruism refers to SWB-improvements that result from the increased financial well-being of neighbors.
} 
The literature unambiguously suggests that $\frac{d V}{d Y^{A}}$ is positive (utility increases in own income). In contrast, the sign of $\frac{d V}{d Y^{B}}$ is ambiguous:

$$
\frac{d V}{d Y^{B}}=\left[\left(\frac{\partial V}{\partial P G^{A}} \frac{\partial P G^{A}}{\partial Y^{B}}\right)+\left(\frac{\partial V}{\partial C L^{A}} \frac{\partial C L^{A}}{\partial Y^{B}}\right)+\left(\frac{\partial V}{\partial E^{A}} \frac{\partial E^{A}}{\partial Y^{B}}\right)+\left(\frac{\partial V}{\partial Y^{B}}\right)\right]
$$

The first term, $\left(\frac{\partial V}{\partial P G^{A}} \frac{\partial P G^{A}}{\partial Y^{B}}\right)$, is positive, as public goods are increasing in neighbors' income $\left(\frac{\partial P G^{A}}{\partial Y^{B}}>0\right)$ and utility is increasing in public goods $\left(\frac{\partial V}{\partial P G^{A}}>0\right)$. The second term, $\left(\frac{\partial V}{\partial C L^{A}} \frac{\partial C L^{A}}{\partial Y^{B}}\right)$, is negative, as the cost of living is increasing in neighbors' income $\left(\frac{\partial C L^{A}}{\partial Y^{B}}>0\right)$ and utility is decreasing in the cost of living $\left(\frac{\partial V}{\partial C L^{A}}<0\right)$. The third term, $\left(\frac{\partial V}{\partial E^{A}} \frac{\partial E^{A}}{\partial Y^{B}}\right)$, is ambiguous. As in Hirschman \& Rothschild (1973) and Senik (2008), it is assumed that utility is increasing in expectations of own future income $\left(\frac{\partial V}{\partial E^{A}}>0\right)$, but it is unclear whether expectations of one's own future income are increasing or decreasing in neighbors' income ( $\frac{\partial E^{A}}{\partial Y^{B}}$ is ambiguous). For example, if the tunnel effect holds, then $\frac{\partial E^{A}}{\partial Y^{B}}>0$; but if the zero-sum effect holds, then $\frac{\partial E^{A}}{\partial Y^{B}}<0$. (In Senik (2008) our third term is assumed to be positive and represents the tunnel effect.) Finally, the fourth term, $\frac{\partial V}{\partial Y^{B}}$, represents the direct effect of $Y^{B}$ on $V$, and its sign is ambiguous, as well. If the RIH dominates, then utility is decreasing in neighbors' income; if altruism dominates, then utility is increasing in neighbors' income. In summary, the effect of neighbors' income on utility is a priori ambiguous and will depend on the signs and relative magnitudes of the channels. Thus, an empirical analysis is warranted.

Our model is not necessarily exhaustive. The included channels are chosen because they have each been discussed in the literature, and they together provide a broad spectrum of how neighbors' income and SWB might be related. In our empirical analysis, we use "channel-proxies" in an attempt to test for the distinct channels. We find evidence that 
the effect of neighbors' income on utility is mediated by three of the four channels: public goods, cost of living, and direct effects.

Lastly, the strength of a channel is presumably dependent on the reference group. For example, public goods may be important in narrowly defined geographic areas, as individuals benefit from local public goods. In contrast, cost of living may be more important in less narrowly defined geographic areas, as much of the variance in cost of living is determined by integrated regional economies. Thus, there can be a positive relationship between neighbors' income and utility with one reference group and a negative relationship with another. In our empirical analysis, we find evidence of such a pattern, with positive channels dominating locally and negative channels dominating regionally.

\section{Data and methods}

\subsection{Econometrics}

We begin with a brief presentation of a standard SWB equation:

$$
y_{\mathrm{i}}=\alpha_{0}+\alpha_{1} X_{\mathrm{i}}+\varepsilon_{\mathrm{i}}
$$

for $i=1, \ldots, I$, where $i$ indexes individuals. The dependent variable, $y_{i}$, is the SWB of the $i^{\text {th }}$ respondent; $X_{i}$ is a vector of SWB-correlates of the $i^{\text {th }}$ respondent, including demographic and socioeconomic characteristics; and $\varepsilon_{\mathrm{i}}$ captures unobserved characteristics and measurement error (Graham, 2005). In the context of this paper, the standard equation can be modified to explicitly illustrate the coefficients on income, both neighbors' and own:

$$
y_{i}=\beta_{0}+\beta_{1} \ln \left(\text { NeighborInc }_{i}\right)+\beta_{2} \ln \left(\text { OwnInc }_{i}\right)+\mathrm{D}_{i} \gamma+\mu_{\mathrm{S}}+\mu_{M}+\mu_{C}+\mu_{t}+\varepsilon_{i}
$$


The independent variable, NeighborInc $i$, is the $i^{\text {th }}$ respondent's reference income; and OwnInci, is the $i^{\text {th }}$ respondent's self-reported income. $D_{i}$ is a vector of SWB-correlates of the $i^{\text {th }}$ respondent, including demographic and socioeconomic characteristics: gender, age, race, education, employment, marital status, and parental status. The model also includes state, MSA, county, and time (day, month, and year of interview) fixed effects ( $\mu_{S}, \mu_{M}$, $\mu_{C}$, and $\mu_{t}$, respectively). Standard errors are adjusted for arbitrary forms of heteroskedasticity as well as the non-random clustering of observations by ZIP code. The coefficient of interest, $\beta_{1}$, captures the relationship between neighbors' income and SWB, holding constant own income. A positive (negative) estimate of $\beta_{1}$ indicates that SWB is increasing (decreasing) in neighbors' income. Estimates of $\beta_{1}$ are commonly reported in the literature, and support for the RIH is often based on such estimates being negative.

We first measure reference income as median income in the $i^{\text {th }}$ respondent's ZIP code, and second, as median income in the $i^{\text {th }}$ respondent's MSA. When using ZIP-code median income, the fixed effects should control for economic and policy shocks at the state, MSA, and county level as well as for any relationship between state, MSA, and county median income and SWB. When using MSA median income, we drop the MSA and county fixed effects due to multicollinearity, as MSAs comprise counties. Further, we do not include ZIP-code fixed effects, as ZIP codes generally do not cross county or MSA lines. (Recall, standard errors are clustered by ZIP code.) Lastly, we estimate equation (4) with both measures of reference income on the right hand side. This is done in an attempt to control for the relationship between ZIP-code median income and SWB - and MSA median income and SWB-simultaneously.

\subsection{Data}

The GHWBI has conducted a telephone survey (landline or mobile) with approximately 1,000 U.S. inhabitants per day in repeated cross-sections since January 2008 using a stratified sampling technique. ${ }^{8}$ Our analysis uses data from 2011 through 2012 , during

\footnotetext{
${ }^{8}$ For full disclosure, Graham is an academic advisor to the Gallup Polls and in that capacity has access to the data.
} 
which time 685,368 individuals were surveyed. Our final sample consists of 456,719 individuals; as explained below, observations missing necessary information were dropped. Summary statistics for the dependent and independent variables included are presented in Tables $1 \mathrm{a}$ and $1 \mathrm{~b}$, respectively.

\subsubsection{Dependent variables}

Various measures of well-being are used as dependent variables, $y_{i}$. Our primary wellbeing measure is an evaluative SWB measure called the Cantril ladder "best possible life" (BPL) index. The item reads: "Please imagine a ladder with steps numbered from 0 at the bottom to 10 at the top. The top of the ladder represents the best possible life for you, and the bottom of the ladder represents the worst possible life for you. On which step of the ladder would you say you personally feel you stand at this time?"9 Figure 2 illustrates the distribution of BPL. We also consider a second evaluative SWB item, an indicator variable for whether respondents report being satisfied (1) or dissatisfied (0) with the city or area where they live. In terms of hedonic SWB, the measures in the GHWBI indicate whether the respondent experienced certain feelings the day before. For each of the feelings (enjoyment, happiness, sadness, stress, and worry), respondents are asked: "Did you experience the following feelings during a lot of the day yesterday? How about ?" An indicator variable is created for each of these feelings.

We also use various health measures as dependent variables. The first is a self-reported health measure that reads: "Would you say your own health, in general, is: poor, fair, good, very good, or excellent?" Possible answers are coded from 1 to 5, respectively. Second, the GHWBI asks respondents: "Have you ever been told by a physician or nurse that you have any of the following: high blood pressure, high cholesterol, diabetes, depression, heart attack, asthma, or cancer?" An indicator variable is created for each of these health markers. Third, the GHWBI contains measures of health-related behaviors, including current smoking, the number of days in the last week the respondent exercised

\footnotetext{
${ }^{9}$ Of the total sample, $0.5 \%$ had missing values for BPL or refused to respond to that item. Those observations were dropped.
} 
at least 30 minutes, and the number of days in the last week the respondent ate at least five fruits or vegetables. Lastly, the GHWBI's height and weight items allow BMI to be calculated.

The evaluative and hedonic SWB measures in the GHWBI have been used to understand similarities and differences between evaluative and hedonic SWB-correlates (e.g., Deaton \& Stone (2013), as discussed in Section 2.4). Using the GHWBI, Kahneman \& Deaton (2010) find that annual income's positive relationship with hedonic SWB is insignificant for income greater than $\$ 75,000$ but find no such satiation point in the positive relationship with BPL. Diener et al. (2010) find a similar pattern using the same questions from the Gallup World Poll.

\subsubsection{Independent variables}

Data about ZIP-code and MSA characteristics come from the U.S. Census Bureau's 2011 and 2012 ACS. The ACS is administered by mail to roughly 2,000,000 households per year and includes questions regarding demographic, economic, financial, housing, and social characteristics. The ACS reports ZIP-code and MSA median incomes that we then match to the GHWBI data. ${ }^{10}$ Median ZIP-code and MSA income are the main measures of neighbors' income; as a robustness check, we calculate ZIP-code and MSA median income from within the GHWBI. The ACS's ZIP-code level median income data is only available as five-year estimates (e.g., 2011 ZIP-code median income is the 2007-2011 median). This is not the case for MSA median income. As a robustness check, we use five-year estimates for MSA median income. Additional analyses use the ACS for other ZIP-code and MSA level statistics, like median rents and income inequality.

To measure own income, we use responses to the GHWBI item: "What is your total MONTHLY household income, before taxes? Please include income from wages and

\footnotetext{
${ }^{10}$ Median ZIP-code income was missing from the ACS for a small number of observations; these observations were dropped. In the sample, 141,175 (20.6\%) respondents did not live in an MSA; these observations were dropped.
} 
salaries, remittances from family members living elsewhere, farming, and all other sources." Eleven possible response-categories are included: under $\$ 60 ; \$ 60-\$ 499 ; \$ 500$ \$999; \$1,000-\$1,999; \$2,000-\$2,999; \$3,000-\$3,999; \$4,000-\$4,999; \$5,000-\$7,499; $\$ 7,500-\$ 9,999 ; \$ 10,000$ and over; and unknown. ${ }^{11}$ Respondents' annual household income variable is calculated as twelve times the midpoint of the corresponding monthlyincome category. While reporting income in discrete categories may introduce noise compared to continuous measures, it is more forgiving in instances of imprecise recall. Importantly, the noise introduced should not bias our estimation of $\beta_{1}$. The only plausible systematic error introduced would be in top-coded income. As such, all regressions include an indicator variable for top-coded income.

\section{Results}

\subsection{Baseline results}

\subsubsection{Evaluative SWB: Best possible life and satisfaction with city}

Starting with ZIP-code median income as the measure of neighbors' income and BPL as the measure of SWB, the coefficient on neighbors' income is positive and significant $(b=$ $0.08, \mathrm{t}=7.2$ ) (see Table 2a, Column (1)). The magnitude indicates that doubling neighbors' income is associated with a 0.08 "step" increase in BPL. Recall that Column (1) conditions on known BPL-correlates, and county, MSA, state, and time fixed effects. This should control for observable individual characteristics; economic or policy shocks at the county, MSA, and state levels; and the relationships between county, MSA, and state median income and BPL. The only plausible causal channel we are not conditioning on is self-selection into geographic areas based on unobservable individual characteristics.

When MSA median income is used to measure neighbors' income, however, the coefficient on neighbors' income is negative and significant $(b=-0.11, t=-4.8)$ (see Table 2a, Column (2)). The magnitude indicates that doubling neighbors' income is

\footnotetext{
${ }^{11}$ Income data was missing for 109,642 (16\%) observations; these observations were dropped.
} 
associated with a 0.11 step decrease in BPL. Recall that when MSA median income is used to measure neighbors' income, we cannot include MSA, county, or ZIP-code fixed effects. Thus, in Column (2), the positive relationship between ZIP-code median income and BPL is not controlled for. To partially control for this, we estimate equation (4) with both ZIP-code and MSA median incomes on the right hand side (full model). The coefficients on ZIP-code and MSA median income are $0.06(\mathrm{t}=6.1)$ and $-0.17(\mathrm{t}=-6.8)$, respectively (see Table $2 \mathrm{a}$, Column (3)). ${ }^{12}$

The Column (1) and (3) ZIP-code median-income coefficients are statistically indistinguishable from each other. This is not surprising, as Column (1) includes state, MSA, and county fixed effects, which should control for the negative relationship between MSA median income and BPL. In contrast, the MSA median-income coefficient is significantly greater in magnitude in Column (3) than (2), likely because the positive relationship between ZIP-code median income and BPL is partially controlled for in Column (3), but not in Column (2). It should be noted that despite their correlation (Spearman $=0.50, p=0.00)$, inclusion of both ZIP-code and MSA median incomes in Column (3) does not result in the increasing standard errors one would expect from multicollinearity. The standard errors on ZIP-code and MSA median income in Column (3) are similar to the corresponding standard errors in Columns (1) and (2).

In sum, the above results indicate that the positive channels (public goods, tunnel effect, and/or altruism) dominate in the relationship between ZIP-code median income and BPL; and that the negative channels (cost of living, zero-sum effect, and/or RIH) dominate in the relationship between MSA median income and BPL. It should be noted that the sign of the dominant channels does not imply that the dominated channels are not operant, merely that the gross effect of the dominant channels exceeds the gross effect of the dominated channels.

\footnotetext{
${ }^{12}$ It warrants mention that if one simply regresses BPL on ln ZIP-code or MSA median income, the coefficients are positive and highly significant $(b=0.37, t=39.6$; and $b=0.27, t=13.2$, respectively). If one then adds own income, then the others' income coefficients are roughly halved (compared to the Column (1) and (2) coefficients) to $0.04(\mathrm{t}=4.0)$ and $-0.05(\mathrm{t}=-2.5)$, respectively.
} 
Comparing the own and neighbors' income coefficients in Column (3) suggests that increasing ZIP-code median income increases BPL at a fifth of the rate of increasing own income; and increasing MSA-median income reduces BPL at half the rate of increasing own income. ${ }^{13}$ These values are comparable to Deaton \& Stone (2013) and Brodeur \& Fleche (2015), both of which estimate that increasing ZIP-code median income increases evaluative SWB at roughly a quarter the rate of increasing own income. The former (latter) finds that increasing MSA (county)-median income reduces BPL at a fifth (fourth) of the rate of increasing own income. As in these two papers, our results do not align with the aforementioned Luttmer (2005) result that the neighbors-income coefficient is of the same magnitude but opposite sign as the own-income coefficient, or the Kingdon \& Knight (2007) result that the neighbors-income coefficient is of the same sign and greater magnitude than the own-income coefficient. In Clark et al. (2009a), increasing neighborhood median income increases economic satisfaction at roughly $60 \%$ (nine times) the rate of increasing own income when not controlling (controlling) for rank.

Lastly, in Column (4), the full model is estimated using satisfaction with city as the dependent variable. Qualitatively, the results mimic the BPL-results, with satisfaction with city increasing in ZIP-code median income and decreasing in MSA median income. The magnitudes, though, are quite different. Using satisfaction with city as the dependent variable, the ZIP-code median-income coefficient is the same sign as and approximately seven times the magnitude of the own-income coefficient. The MSA median-income coefficient more than offsets the own-income coefficient; the former is twice the latter in magnitude and of opposite sign. In the corresponding analysis using satisfaction with town/city as the dependent variable, Luttmer (2005) finds that the PUMA median-income coefficient is positive and six times the magnitude of the own-income coefficient, similar to our ZIP-code results.

\footnotetext{
13 In all models, doubling own income is associated with a roughly 0.33 step increase in BPL ( $\mathrm{t}>70$ for all specifications in Table 2a), with no evidence of satiation at income levels below the top-coded threshold of $\$ 120,000$. This finding is similar to Kahneman \& Deaton (2010), who are not able to identify a satiation point in the relationship between own income and BPL. It is of course impossible to rule out a satiation point at income higher than $\$ 120,000$ given the enumeration of the income variable. This critique also applies to Kahneman \& Deaton (2010), as the same survey is used.
} 


\subsubsection{Hedonic SWB: enjoyment, happiness, sadness, stress, and worry experienced yesterday}

The pattern of the baseline results is generally supported when the full model is reestimated with hedonic SWB measures in place of BPL (see Table 2b). Specifically, using enjoyment, happiness, or sadness experienced yesterday, ZIP-code median income is SWB-improving, and MSA median income is SWB-diminishing. Using the other two hedonic measures, stress and worry, there is no relationship with ZIP-code median income, and MSA median income is SWB-reducing.

For enjoyment and happiness, the magnitude of the MSA-median income coefficients relative to own-income coefficients align with the magnitudes reported in Luttmer (2005). ${ }^{14}$ Using either measure as the dependent variable, and comparing MSA medianincome and own-income coefficients, we, like Deaton \& Stone (2013) (hedonic SWB results, see Section 2.3), find that the coefficients are of equal magnitude but of opposite sign. ${ }^{15}$ This suggests that, for both measures, an increase in MSA median-income would exactly offset the SWB-improvements associated with an equal-sized increase in own income.

\subsection{Results are consistent across health measures}

We present evidence that the qualitative relationships that we have identified between neighbors' income and both evaluative and hedonic SWB also extend to health. In Table 3 , each row corresponds to a re-estimation of the full model, replacing BPL with the indicated measure of health. We find consistent evidence across the measures that health is increasing in ZIP-code median income and decreasing in MSA median income.

\footnotetext{
14 The Luttmer (2005) result reported in Section 2.1 - that the coefficient on PUMA median income offsets the coefficient on own income - uses an evaluative SWB measure. In subsequent analyses using hedonic SWB, the PUMA median-income coefficients are insignificant.

15 The top-coded own-income coefficients indicate that the relationship between own income and hedonic SWB is subject to a satiation point; recall that no such satiation point was identified with BPL. The coefficients are either insignificant (e.g., enjoyment) or indicate that top-coded income is associated with reduced hedonic SWB (e.g., stress). This again is consistent with Kahneman \& Deaton (2010).
} 
Specifically, Column (1) shows that ZIP-code median income is positively related to selfreported health and exercise and negatively related to BMI, smoking, and the incidence of asthma, depression, diabetes, heart attack, high blood pressure, and high cholesterol. The only evidence of well-being decreasing in ZIP-code median income is the negative relationship between ZIP-code median income and healthy eating. There is no significant relationship between ZIP-code median income and incidence of cancer.

Following the pattern of the baseline results, Column (2) shows that MSA median income is negatively related to self-reported health and exercise and positively related to incidence of depression. The only evidence of well-being increasing in MSA median income is the negative relationship between MSA median income and BMI and incidence of diabetes and high blood pressure. ${ }^{16}$ There is no significant relationship between MSA median income and smoking, healthy eating, or incidence of asthma, cancer, heart attack, or high cholesterol.

For most measures of health, ZIP-code median-income coefficients are each of the same sign as and of similar or greater magnitude than the own-income coefficient, suggesting that for these measures neighbors' income is at least as important as own income. The only exception is healthy eating. The relationship between the magnitude of the MSA median-income coefficients relative to own-income coefficients varies. For example, the MSA median-income coefficient for exercise (incidence of depression) more (less) than offsets the own-income coefficient. Luttmer (2005) finds that an increase in neighbors' income roughly offsets an equal-sized increase in own-income. ${ }^{17}$

\subsection{Conditioning on channel-proxies}

In an attempt to more explicitly gauge the relative magnitudes of the explanatory channels, in this section we condition the analyses on "channel-proxies." First, we use

\footnotetext{
${ }^{16}$ These results may suggest that neighbors' income tends to be associated with improvements in measures related to the consequences of obesity. This may be mediated by the availability of healthy food and exercise options in areas with higher income.

${ }^{17}$ Empirical evidence on the relationship between neighbors' income and health is mixed in the literature. Both positive and negative associations have been identified, and some researchers have found no discernible association (see Blanco-Perez, 2012).
} 
ZIP-code and MSA means of BPL and satisfaction with city as proxies for public goods (means are calculated excluding the respondent's BPL and satisfaction with city). If the relationship between neighbors' income and BPL is fully mediated by pubic goods (and if neighbors' BPL or satisfaction with city captures the effect of public goods), then conditioning on neighbors' BPL or satisfaction with city should eliminate the estimated relationship between neighbors' income and BPL. We can also consider the BPL of neighbors itself a public good, resulting in utility spillovers.

The full model is estimated with ZIP-code and MSA means of BPL and satisfaction with city included as covariates and BPL as the measure of well-being. Comparing Columns (1) and (2) in Table 4a, the ZIP-code and MSA median-income coefficients both become more negative: the ZIP-code median-income coefficient becomes insignificant (from $b=$ $0.06, \mathrm{t}=6.2$ to $\mathrm{b}=0.01, \mathrm{t}=0.8)$, and the MSA median-income coefficient increases in magnitude (from $\mathrm{b}=-0.17, \mathrm{t}=-6.8$, to $\mathrm{b}=-0.25, \mathrm{t}=-9.5$ ). The coefficients on ZIP-code mean BPL $(b=0.09, t=9.1)$, ZIP-code mean satisfaction with city $(b=0.15, t=3.9)$, and MSA mean BPL $(b=0.32, t=8.8)$ are all positive and significant. Taken together, this suggests that BPL is increasing in public goods at the ZIP-code and MSA levels, and that conditioning on the positive impact of public goods renders more negative the residual estimated impact of neighbors' income on BPL. Our results align with the results of Brodeur \& Fleche (2015), who find that controlling for public goods reduces and renders insignificant the ZIP-code median income coefficient and renders more negative the county median-income coefficient; our results contradict Kingdon \& Knight (2007), who find that the clusters' average-income coefficient is still positive and significant when a host of public goods are controlled for. ${ }^{18}$

\footnotetext{
18 As noted in Section 2.1, Kingdon \& Knight (2007) point out that they cannot rule out unobserved public goods; the same can be said for Brodeur \& Fleche (2015). (In the former, none of the observed pubic goods controlled for is statistically significantly associated with SWB; the latter does not report the publicgoods coefficients.) Our approach does not rely on the observability of public goods and allows for utility spillovers. Brodeur \& Fleche (2015) include as public goods the unemployment and poverty rates and neighbors' demographic variables (e.g., marital status and education), suggestive of utility spillovers. Because they do not report coefficients, it is not clear which specific sub-channel's relationship to SWB is strongest.
} 
Second, we attempt to condition on the cost-of-living channel using ZIP-code and MSA median rents, as housing costs are the single largest household expense in the U.S. (Bureau of Labor Statistics, 2014). The full model is estimated with ZIP-code and MSA median rents as covariates. ${ }^{19}$ As shown in Column (3) of Table 4a, the ZIP-code medianincome coefficient is unaffected by the addition of these correlates (from $b=0.06, t=6.2$ to $b=0.06, t=4.1)$. In contrast, the MSA median-income coefficient becomes insignificant (from $b=-0.17, t=-6.8$ to $b=0.01, t=-0.2$ ). Further, the MSA median-rent coefficient is negative and significant $(b=-0.23, t=-4.8)$, and the ZIP-code median-rent coefficient is insignificant $(b=0.01, t=0.6)$. Taken together, this indicates that, at the MSA-level, BPL is decreasing in cost of living, and that conditioning on cost of living eliminates the observed negative relationship between neighbors' income and BPL. This suggests that cost of living explains the observed negative relationship between MSA median income and BPL. These results contradict both Luttmer (2005) and Brodeur \& Fleche (2015). In the former, the negative relationship between neighbors' income and SWB continues to hold when housing-price controls are added; in the latter, all specifications and results include housing-price controls.

Third, we attempt to condition on the expectations-of-future-income channel using BPLin-five-years as a proxy. ${ }^{20}$ If the relationship between neighbors' income and BPL is fully mediated by changes in expectations of future income (and if BPL-in-five-years captures the expected effect of future income on future BPL), then conditioning on BPL-in-fiveyears should eliminate the estimated relationship between neighbors' income and current BPL. The full model is estimated with BPL-in-five-years as a covariate. As shown in Column (4) of Table 4a, the ZIP-code median-income and MSA median-income coefficients are unaffected (ZIP code: from $b=0.06, t=6.2$ to $b=0.05, t=5.7$; and MSA: $b=-0.17, t=-6.8$ to $b=-0.19, t=-9.0)$. This suggests that, despite the significant association of current BPL and BPL-in-five-years $(b=0.46, t=302.7)$, the expectations-

\footnotetext{
19 The model also includes indicator variables for the ZIP-code median rent being bottom- or top-coded. The bottom-code is $\$ 100$ per month; the top-code is $\$ 2,000$ per month. No MSA median rents are bottomor top-coded.

${ }^{20}$ The question uses the same response scale as current BPL; specifically, it reads, "Please imagine a ladder with steps numbered from zero at the bottom to 10 at the top. The top of the ladder represents the best possible life for you and the bottom of the ladder represents the worst possible life for you. On which step do you think you will stand about five years from now?"
} 
of-future-income channel does not explain the relationship between neighbors' income and BPL at either the ZIP-code or MSA level.

Finally, in Column (5) of Table 4a, we attempt to control for the three channels simultaneously by estimating the full model with all channel-proxies included. If the channel-proxies are successfully conditioning on the channels, then the residual relationship represents an approximation of the direct effect of neighbors' income on BPL. The results indicate that the relationship between neighbors' income and BPL becomes insignificant at both the ZIP-code and MSA levels $(b=0.01, t=0.7$; and $b=$ $0.05, \mathrm{t}=-1.2$ ). This suggests that either there are no direct effects, or that any effects of RIH are offset by altruism.

In Table 4b, we repeat the analysis from Column (5) of Table 4a; each column corresponds to a different hedonic-SWB dependent variable. For enjoyment and happiness controlling for the three channels maintains a positive and significant ZIP-code median-income coefficient and renders the MSA median-income coefficient insignificant. For sadness, stress, and worry, controlling for the three channels produces median-income coefficients that are SWB-improving and significant at both the ZIP-code and MSA levels. As with BPL, these results suggest that either there is no RIH, or that any effects of RIH are offset (or more than offset) by altruism.

\subsection{Subgroup analyses}

Our results above indicate that the relationship between neighbors' income and SWB depends on the geographic proximity of the reference group. The relationship may also depend on respondents' characteristics. For each of the demographic and socioeconomic characteristics included in the full model, we conduct subgroup analyses by interacting subgroups with neighbors' and own income, using BPL as the dependent variable. When the subgroup indicator is not binary, we create a binary indicator variable and add it as a covariate.

First, we consider four distinct income-categories based on whether respondents are lowor high-income and reside in low- or high-income ZIP codes. Low- (high-) income 
respondents are defined as those whose own income is less than (greater than) ZIP-code median income. Low- (high-) income ZIP codes are defined as those with ZIP-code median incomes less than (greater than) MSA median income. The four categories of respondents are thus low-income respondents in low-income ZIP codes (LL), low-income respondents in high-income ZIP codes (LH), high-income respondents in low-income ZIP codes (HL), and high-income respondents in high-income ZIP codes (HH). Column (1) of Table 5 reports median incomes for each subgroup. Separating high- and lowincome respondents based not just on their income relative to their ZIP code's but also on their ZIP code's income relative to the MSA's controls for absolute-income differences that would otherwise be masked. For example, Column (1) shows that LL respondents have substantially lower median incomes than LH respondents $(\$ 18,000$ versus $\$ 42,000)$; LL median income is also much closer to federal poverty thresholds.

Panel (A), Columns (2) and (3) of Table 5 show that for all income-subgroups except LL, the qualitative baseline results - that BPL increases with ZIP-code median income and decreases with MSA median income-hold. For LL respondents, the opposite pattern is observed: BPL decreases with ZIP-code median income and increases with MSA median income, so that negative channels dominate locally and positive channels dominate regionally.

Why might this be? Estimating the full model for LL respondents and including all the channel-proxies, the ZIP-code median-income coefficient is negative and statistically significant $(b=-0.17, t=-4.0)$, suggesting that the RIH dominates altruism for LL respondents (see Panel (B), Column (2)). In the corresponding analysis for non-LL respondents, the ZIP-code median-income coefficient is insignificant $(b=0.01, t=1.2)$, suggesting that the RIH is not operant or is offset by altruism (see Panel (B), Column (2)). It may be that LL respondents feel more alienated from their local communities than do non-LL respondents, making them more susceptible to the RIH.

Comparing the public-goods channel-proxies for LL and non-LL respondents, the MSA mean-BPL coefficient is more than two times larger in magnitude for LL respondents than for non-LL respondents $(b=0.47, t=5.1$ versus $b=0.18, t=5.0)$ (estimates not 
reported in table). The ZIP-code mean-BPL coefficient is insignificant for LL respondents $(b=0.01, t=0.6)$; in contrast, it is positive and significant for non-LL respondents $(b=0.05, t=6.3)$. It may be that $L L$ respondents are more dependent on regional public goods than local public goods (and likely unable to afford private substitutes for public goods). The only contradictory evidence is that the ZIP-code mean satisfaction-with-city coefficient is larger in magnitude for LL than for non-LL respondents $(b=0.31, t=3.9$ versus $b=0.19, t=5.0)$. Finally, the MSA mean satisfaction-with-city coefficients for both LL and non-LL respondents are insignificant.

Luttmer (2005) uses a similar interaction analysis to determine whether the PUMA median-income coefficients are different for those above and below their PUMA median incomes; no difference is observed. It also bears note that Luttmer (2005) finds no difference in the own-income coefficient for those above and below their PUMA median incomes. In contrast, Panel (A), Column (4) of Table 5 shows that the own-income coefficients for $\mathrm{HL}$ and $\mathrm{HH}$ respondents are roughly double the magnitude of LL and LH respondents. Brodeur \& Fleche (2015) separate their sample by whether household income is above or below the ZIP-code median. Their baseline results hold for those whose income is below the ZIP-code median, with ZIP-code median income even more SWB-improving than for the pooled sample. For those whose income is above the ZIPcode median, ZIP-code median income is less SWB-improving than for the pooled sample (and only marginally significant), and county median income is not significantly associated with SWB. Kingdon \& Knight (2007) separate their sample by whether household income is above or below the poverty line. Their baseline results hold in both cases, but the cluster-income coefficient is roughly two times greater for those above than below the poverty line. In line with our results, both Brodeur \& Fleche (2015) and Kingdon \& Knight (2007) find that the own-income coefficient is greater for their highthan low-income categories.

Panel (A) of Table 6 presents coefficients for neighbors' and own income for married and unmarried respondents. While our baseline results are qualitatively upheld for married respondents, the ZIP-code median income coefficient for unmarried respondents is insignificant. Further, both the ZIP-code and MSA median-income coefficients are 
significantly smaller in magnitude for unmarried than married respondents $(p=0.00$ for each). In Luttmer (2005), the main result and baseline regression are for married respondents only. In subsequent subgroup analyses, the PUMA median-income coefficient is insignificant for never-married and widowed respondents.

The relationship between neighbors' income and BPL is subgroup-variant for other demographic and socioeconomic characteristics, as well. For example, ZIP-code medianincome coefficients are significantly different for non-whites versus whites, those with at most versus more than a high school education, and the unemployed versus employed. The baseline ZIP-code result qualitatively holds for whites and for those with more than a high school education, but the ZIP-code median-income coefficient is insignificant for non-whites and negative and significant for those with at most a high school education. While the baseline ZIP-code result qualitatively holds for both the unemployed and employed, the coefficient for the unemployed is significantly larger in magnitude. It should be noted that the subgroup-variant ZIP-code median-income results by marital status, race, and education might be related to the subgroup-variant results by income, as LL respondents are disproportionately unmarried (69\%), non-white (28\%), and have at most a high school degree (41\%); the corresponding proportions for non-LL respondents are $40 \%, 13 \%$, and $18 \%$, respectively (p-values of all three differences are $0.00)$.

The baseline MSA result qualitatively holds for all subgroups except those with at most a high school education, for whom the MSA median-income coefficient is insignificant. MSA median-income coefficients are significantly different for non-whites versus whites, those with at most versus more than a high school education, the unemployed versus employed, and females versus males. The baseline ZIP-code and MSA median-income coefficients do not vary by age or parental status. Lastly, there are subgroup differences in own-income coefficients, but for all subgroups the baseline own-income result qualitatively holds. 


\subsection{Other specification checks}

In this section, we present the results of a series of specification checks that test the limits of our baseline results, using BPL as the dependent variable (see Table 7; Column (1) repeats the baseline results from the full model). In Column (2), we estimate the full model, replacing MSA median income with county median income (this data also comes from the ACS). Compared to Column (1), the ZIP-code median-income coefficient is statistically indistinguishable $(b=0.07, t=6.1$ versus $b=0.06, t=6.2)$, and the county median-income coefficient is smaller in magnitude than the MSA median-income coefficient $(b=-0.10, t=-5.2$ versus $b=-0.17, t=-6.8)$. That the county median-income coefficient lies between the ZIP-code and MSA median-income coefficients is not surprising as counties are geographic areas with populations between those of ZIP codes and MSAs (ZIP codes 7,500 inhabitants; counties 100,000; MSAs 850,000). In Column (3), we estimate the full model with ZIP-code, county, and MSA median income on the right hand side simultaneously. The county median-income coefficient becomes insignificant ( $b=-0.4, t=-1.6)$. Comparing Columns (1) and (3), the ZIP-code and MSA median-income coefficients are unaffected $(b=0.06, t=6.2$ versus $b=0.07, t=6.3$; and $b=-0.17, t=-6.8$ versus $b=-0.14, t=-4.2$ ). Further, in Column (3), MSA median income has a significant relationship with BPL, while county median income does not. This validates our baseline choice of MSA (over county) as the reference group.

In Column (4) of Table 7, we calculate ZIP-code and MSA median incomes from within the GHWBI instead of using the ACS-reported medians. The ZIP-code and MSA median-income coefficients are unaffected, indicating robustness to the measurement of neighbors' income. Further, this addresses the potential problem that the positive ZIPcode coefficient in our baseline result is due to neighbors' income serving as a proxy for noisily measured individual income, as the ZIP-code median incomes calculated from the GHWBI presumably contain the same noise as the individual-income data. In Column (5), we estimate the full model, replacing the 1-year estimate of MSA median income from the ACS with the 5-year estimate of MSA median income from the ACS (recall that ZIP-code median income from the ACS was estimated over a 5-year period). The ZIPcode and MSA median-income coefficients are unaffected. In Column (6), we estimate 
the full model with ZIP-code and MSA Gini coefficients as covariates (this data also comes from the ACS), and our baseline results are qualitatively unaffected. Lastly, Columns (7) and (8) restrict the sample to respondents who live in ZIP codes with at least 30 and 60 observations in the GHWBI, respectively, and the baseline results are unaffected. Columns (4)-(8) rule out that our results are driven by measurement error in reference income, the distribution of reference income, or small ZIP codes (where reference income might be more salient). Taken together, Table 7 indicates the robustness of the baseline results.

\section{Discussion}

The current research contributes to the relative-income literature along four dimensions. First, we propose a theoretical framework that acknowledges the complexity of the relationship between neighbors' income and utility. In it, we identify four explanatory channels through which neighbors' income can impact utility: public goods, cost of living, expectations of future income, and direct effects. Based on the framework, the net effect of neighbors' income on utility is ex ante indeterminate and depends on the relative strengths of the channels. Second, we conduct empirical analyses to estimate the relationship between neighbors' income and various measures of evaluative and hedonic SWB and find that the relationships are generally positive locally and negative regionally. Third, we find that this pattern extends to well-being as measured by various health-related indices. Fourth, we condition on channel-proxies in an attempt to isolate the impact of the four explanatory channels on BPL. Our analyses indicate that the public-goods channel is operant at the ZIP-code and MSA levels, and the cost-of-living channel is operant at the MSA-level. The analyses of the expectations-of-future-income channel and direct effects suggest either that these channels are not operant or that the positive and negative sub-channels (tunnel effect versus zero-sum effect and altruism versus RIH) fully offset each other. Fifth, subgroup analyses show that the baseline results are reversed for low-income respondents in low-income ZIP codes: for these respondents, the relationship between neighbors' income and SWB is negative locally and positive regionally; for this vulnerable group (median income $=\$ 18,000$ ), the public- 
goods channel appears to be operant regionally but not locally, while the RIH dominates locally.

Taken together, our results underscore the need to be cautious when generalizing reference-dependent outcomes, as the choice of reference group can affect not just the magnitude of the relationship between neighbors' income and utility, but also its direction. Further, our framework organizes variant explanatory channels. Our empirical results also corroborate those in Deaton \& Stone (2013), Brodeur \& Fleche (2015), and Clark et al. (2009a) which find that the relationship between neighbors' income and SWB is increasingly negative as the geographically-based reference group expands in population and size from the ZIP-code level. We cannot speak to the inversion of this relationship that Brodeur \& Fleche (2015) identify when analyzing finer levels of geographic proximity than ZIP codes.

We leave it to further research to examine whether the relationship between SWB and the income of other kinds of reference groups (i.e., non-geographic) varies with referencegroup composition (i.e., non-geographic proximity). For example, the SWB-effects of family members' income may differ by age or for nuclear versus non-nuclear family members. The relevant channels for other reference groups may similarly depend on reference-group composition. For example, McBride (2010) conducts a laboratory experiment in which subjects rate their happiness with the results of a penny-matching game played against the computer. Restricting to subjects who are informed of other subjects' results, happiness with one's own results are found to decrease with other's success; this result is interpreted as supportive of the RIH. Subsequent analyses indicate that the result only holds when subjects are informed about players with the same randomly-determined success-probability, i.e., that the result is proximity-dependent.

Similarly, our results do not contradict the dominance of the tunnel effect identified for the U.S. in Senik (2008), as the reference group used there is occupation-based. It is plausible that the income of one's occupational peers is more relevant to, and less noisy a signal of, one's future income than one's geographical neighbors. Further, the 
discrepancy may be due to shifting demographics: Senik (2008) finds that the tunnel effect is stronger for the young than the old, and the median age in the 2011-2012 U.S. GHWBI is roughly ten years older than the 1974-2000 U.S. General Social Survey sample used in Senik (2008). Lastly, the discrepancy may be due to circumstances that shift the relationship between others' income and expectations of own future income. Senik shows that the effect of others' income on SWB is negative (positive) in Poland pre- (post-) transition. This is in line with Hirschman \& Rothschild (1973), who explicitly assume that the tunnel effect has a shelf-life if positive expectations of future income go unrealized. One can speculate that the 2007-2008 financial crisis and increased awareness of middle-class income stagnation and of the concentration of economic gains by the one percent may have resulted in the zero-sum effect offsetting the tunnel effect.

It should be noted that while we use the median of the income distribution in respondents' geographic areas as reference income, there is no reason to assume that only the first moment of the distribution is related to well-being. A substantial literature concerns the relationship between income inequality and SWB (e.g., Alesina et al., 2004; Graham \& Felton, 2006; Oishi et al., 2011; Van Praag \& Ferrer-i-Carbonell, 2009). While it is shown in Section 5.5 that the baseline results hold controlling for ZIPcode and MSA Gini coefficients, the current paper does not present a thorough analysis of the income-inequality-SWB relationship. We directly examine this complex relationship in a separate paper (Ifcher et al., 2016).

Our results also resonate with recent evaluations of the U.S. Moving to Opportunity (MTO) demonstration (Chetty et al., 2015; Ludwig at al., 2012). In the mid-1990s, some families living in public or section-8 housing in low-income neighborhoods were given the opportunity to apply to MTO. Participants were randomized into the control group or one of two treatment groups - one offered vouchers to move anywhere and the other exclusively to low-poverty neighborhoods. While there is no evidence that treatment improves economic conditions after fifteen years (e.g., income, welfare dependency, etc.), treatment is associated with significant evaluative-SWB gains, marginally significant mental-health gains, and significant reductions in obesity and diabetes 
(Ludwig et al., 2012). The SWB-increase associated with moving to a neighborhood with a standard-deviation lower poverty rate is the same as a $67 \%$ increase in own income. Again, these effects are without any identifiable increase in own income and cannot be explained by RIH, suggesting the dominance of other explanatory channels (e.g., public-goods). These results contradict the RIH and echo our subgroup analyses, which show that the ZIP-code median-income coefficient is negative for LL respondents and positive for LH respondents. In this spirit, the New York Times published an article on the effects of the rapidly rising incomes in the Chelsea neighborhood of New York City. Discussing the pros and cons of her changing neighborhood, a public-housing resident concludes, "I'd rather have Chelsea as it is today.... There's more people.... It's brighter, it's beautiful, it's more inviting than it used to be." (New York Times, October 23, 2015) 


\section{References}

Alesina, A. Di Tella, R., \& MacCulloch, R. (2004). Inequality and happiness: Are Europeans and Americans different? Journal of Public Economics, 88 (9-10 August), pp. 2009-2042.

Angner, Erik. (2010). Subjective well-being. Journal of Socio-Economics, 39: 361-368.

Benjamin, D.J., Heffetz, O., Kimball, M.S., \& Rees-Jones, A. (2012). What Do You Think Would Make You Happier? What Do You Think You Would Choose? American Economic Review, 102(5): 2083-2110.

Benjamin, D.J., Heffetz, O., Kimball, M.S., \& Szembrot, N. (2014). Beyond Happiness and Satisfaction: Toward Well-Being Indices Based on Stated Preference. American Economic Review, 104(9): 2698-2735.

Blanchflower, D. G., \& Oswald, A. J. (2004). Well-being over time in Britain and the USA. Journal of Public Economics, 88(7), 1359-1386.

Blanco-Perez, C. (2012). Rethinking the Relative Income Hypothesis. SOEP papers on Multidisciplinary Panel Data Research 501, DIW Berlin, The German Socio-Economic Panel (SOEP).

Brodeur, A., \& Fleche, S. (2015). Neighbors, Income and Well-Being: Evidence from a Multi-scale Analysis. Working Paper.

Bureau of Labor Statistics. (2014). Consumer expenditure - 2013. Press release (dated September 9, 2014). Available at http://www.bls.gov/news.release/pdf/cesan.pdf.

Chetty, R. N. Hendren, \& Katz, L. (2015). The long-term effects of exposure to better neighborhoods: New evidence from the Moving to Opportunity Experiment. Harvard University Working Paper.

Clark, A. E., Frijters, P., \& Shields, M. A. (2008). Relative income, happiness, and utility: An explanation for the Easterlin paradox and other puzzles. Journal of Economic Literature, 46(1): 95-144.

Clark, A.E., Kristensen, N., \& Westergard-Neilsen, N. (2009a). Economic Satisfaction and Income Rank in Small Neighbourhoods. Journal of the European Economic Association, 7(2-3): 519-527.

Clark, A.E., Kristensen, N., \& Westergård-Nielsen, N. (2009b). Job satisfaction and coworker wages: Status or signal? Economic Journal, 119: 430-447. 
Clark, A.E., \& Senik, C. (2012). Income comparisons in Chinese villages. In A.E. Clark $\&$ C. Senik, eds. Happiness and Economic Growth: Lessons from Developing Countries (Studies of Policy Reform). Oxford: Oxford University Press.

Dahlin, M.B., Kapteyn, A., \& Tassot, C. (2014). Who are the Joneses? CESR-Schaeffer Working Paper No. 2014-004.

Daly, M.C., \& Wilson, D.J. (2009). Happiness, unhappiness, and suicide: An empirical assessment. Journal of the European Economic Association, 7(2-3): 539-549.

D'Ambrosio, C., \& Frick, J.R. (2012). Individual well-being in a dynamic perspective. Economica, 79: 284-302.

Davis, J.A. (1959). A formal interpretation of the theory of relative deprivation. Sociometry, 22: 280-296.

Deaton, A., \& Stone, A.A. (2013). Two happiness puzzles. American Economic Review, 103(3): 591-597.

Diener, E., Suh, E.M., Lucas, R.E., \& Smith, H.L. (1999). Subjective well-being: Three decades of progress. Psychological Bulletin, 125(2): 276-302.

Diener, E., Lucas, R., Schimmack, U., \& Helliwell, J. (2009). Well-Being for Public Policy. Oxford: Oxford University Press.

Diener, E., Kahneman, D., Tov, W., \& Arora, R. (2010). Income's association with judgments of life versus feelings. In E. Diener, J.F. Helliwell, \& D. Kahneman, eds. International Differences in Well-Being. Oxford: Oxford University Press.

Di Tella, R., \& MacCulloch, R. (2006). Some uses of happiness data in economics. Journal of Economic Perspectives, 20(1): 25-46.

Di Tella, R., MacCulloch, R.J., \& Oswald, A.J. (2001). Preferences over inflation and unemployment: Evidence from surveys of happiness. American Economic Review, 91(1): 335-341.

Duesenberry, J. S. (1949). Income, Saving and the Theory of Consumer Behaviour. Cambridge: Harvard University Press.

Easterlin, R.A. (1974). Does economic growth improve the human lot? Some empirical evidence. In P.A. David \& M.W. Reder (eds). Nations and Households in Economic Growth: Essays in Honor of Moses Abramovitz. New York: Academic Press, Inc.

Ferrer-i-Carbonell, A. (2005). Income and well-being: An empirical analysis of the comparison income effect. Journal of Public Economics, 89(5-6): 997-1019. 
FitzRoy, F., Nolan, M.N., Steinhardt, M.F., \& Ulph, D. (2014). Testing the tunnel effect: Comparison, age and happiness in UK and German Panels. IZA Journal of European Labor Studies: 3(24): 1-30.

Frank, R.H. (1985). The demand for unobservable and other nonpositional goods. American Economic Review, 75(1): 101-116.

Frank, R.H. (2012). The Easterlin paradox revisited. Emotion, 12(6): 1188-1191.

Glaeser, E.L., Gottlieb, J.D., \& Ziv, O. (2016). Unhappy cities. Journal of Labor Economics, 34(S2): S129-S182.

Graham, C. (2005). The economics of happiness. World Economics, 6(3): 41-55.

Graham, C., \& Felton, A. (2006). Inequality and happiness: insights from Latin America. Journal of Economic Inequality, 4(1): 107-122.

Helliwell, J.F., Barrington-Leigh, C.P., Harris, A., \& Huang, Haifang. (2010). International Evidence on the Social Context of Well-Being. In E. Diener, J.F. Helliwell, \& D. Kahneman, eds. International Differences in Well-Being. Oxford: Oxford University Press.

Helliwell, J., Layard, R., \& Sachs, J. World Happiness Report 2012. New York: The Earth Institute, Columbia University.

Hirschman, A. O., \& Rothschild, M. (1973). The changing tolerance for income inequality in the course of economic development. Quarterly Journal of Economics, 87(4): 544-566.

Ifcher, J., Zarghamee, H., \& Graham, C. (2015). Income inequality and well-being: Evidence from the U.S. Gallup-Healthways Well-Being Index. Working paper.

Kahneman, D., \& Deaton, A. (2010). High income improves evaluation of life but not emotional well-being. Proceedings of the National Academy of Sciences, 107(38): 1648916493.

Kingdon, G. G., \& Knight, J. (2007). Community, comparisons and subjective well-being in a divided society. Journal of Economic Behavior \& Organization, 64(1): 69-90.

Knight, J., Song, L., \& Gunatilaka, R. (2009). The determinants of subjective well-being in rural China. China Economic Review, 20(2): 635-649.

Krueger, A.B., \& Schkade, D.A. (2008). The reliability of subjective well-being measures. Journal of Public Economics, 92(8-9): 1833-1845. 
Ludwig, J., Duncan, G., Gennetian, L. Katz, L, Kessler, R., \& Kling, J. (2012).

Neighborhood effects on the long-term well-being of low-income adults. Science, 337

(6101): 1505-1510.

Luttmer, E. F. (2005). Neighbors as negatives: relative earnings and well-being.

Quarterly Journal of Economics, 120(3): 963-1002.

McBride, M. (2010). Money, happiness, and aspirations: An experimental study. Journal of Economic Behavior \& Organization, 74: 262-276

New York Times. "In Chelsea, a Great Wealth Divide." Mireya Navarro. October, 23, 2015. http://nyti.ms/1S0mydB

O'Donnell, Gus. (2013). Using well-being as a guide to public policy. In J. Helliwell, R. Layard, \& J. Sachs (eds). World Happiness Report 2013. New York: UN Sustainable Development Solutions Network.

Oishi, S., Kesebir, S, \& Diener, E. (2011). Income inequality and happiness.

Psychological Science, 22 (9): 1095-1100.

Pérez-Asenjo, E. (2011). If happiness is relative, against whom do we compare ourselves? Implications for labour supply. Journal of Population Economics, 24(4): 1411-1442.

Senik, C. (2004). When information dominates comparison: Learning from Russian subjective panel data. Journal of Public Economics, 88(9): 2099-2123.

Senik, C. (2008). Ambition and jealousy: Income interactions in the 'Old'Europe versus the 'New' Europe and the United States. Economica, 75(299): 495-513.

Senik, C. (2009). Direct evidence on income comparison and their welfare effects. Journal of Economic Behavior \& Organization, 72: 408-424.

Stiglitz, J.E., Sen, A., \& Fitoussi, J-P. (2010). Mis-Measuring Our Lives. New York: The New Press.

Stone, A., \& Mackie, C. (2013). Subjective Well-Being: Measuring Happiness, Suffering, and Other Dimensions of Experience. Washington D.C.: The National Academies Press.

Van Praag, B., \& Ferrer-Carbonell, A. (2009). Inequality and Happiness. In W. Salverda, B. Nolan, \& T. Smeeding (eds). The Oxford Handbook of Income Inequality. Oxford: Oxford University Press.

Veblen, T. (1899). The Theory of the Leisure Class: An Economic Study of Institutions. New York: Penguin Books, 1994. 
Figure 1: Relationship between neighbors' income and utility

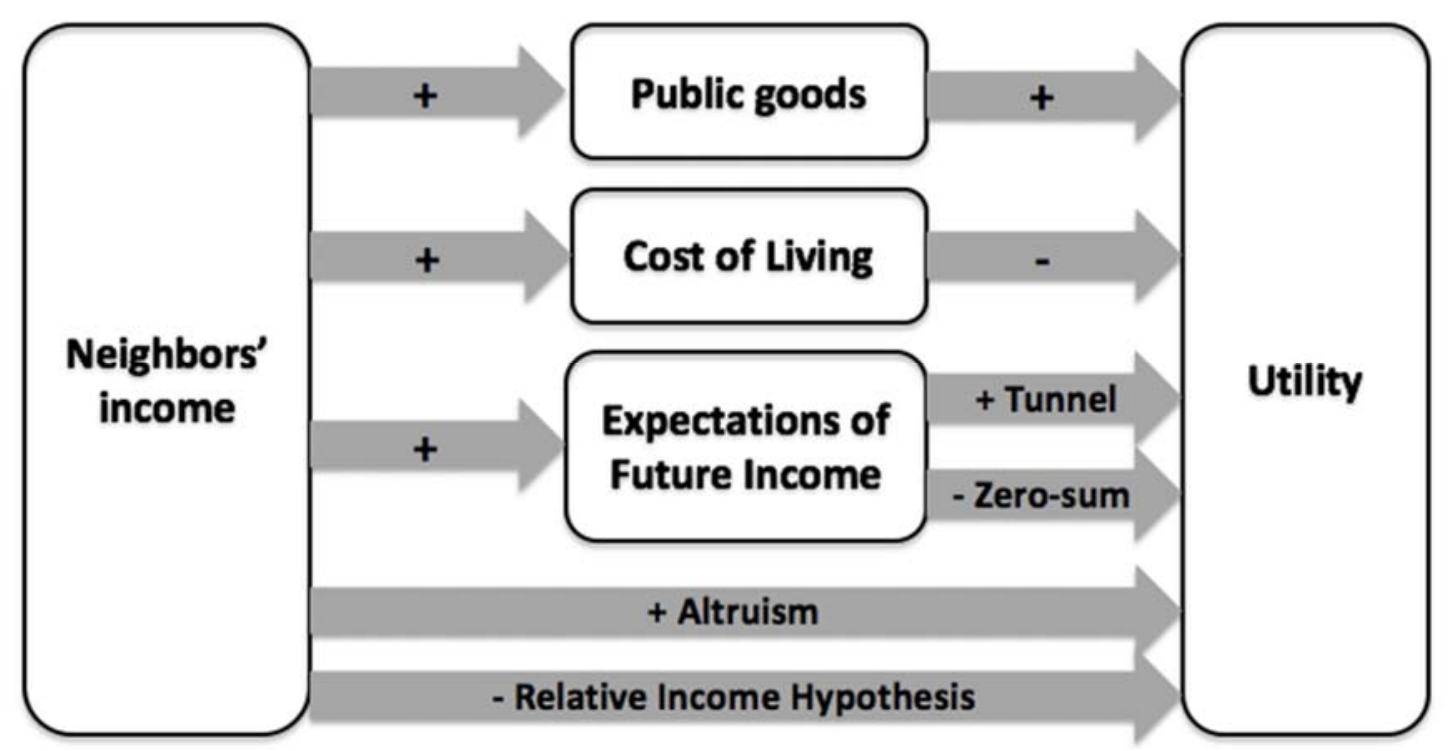


Figure 2: Histogram of BPL (mean and median $=7 ;$ mode $=8$ )

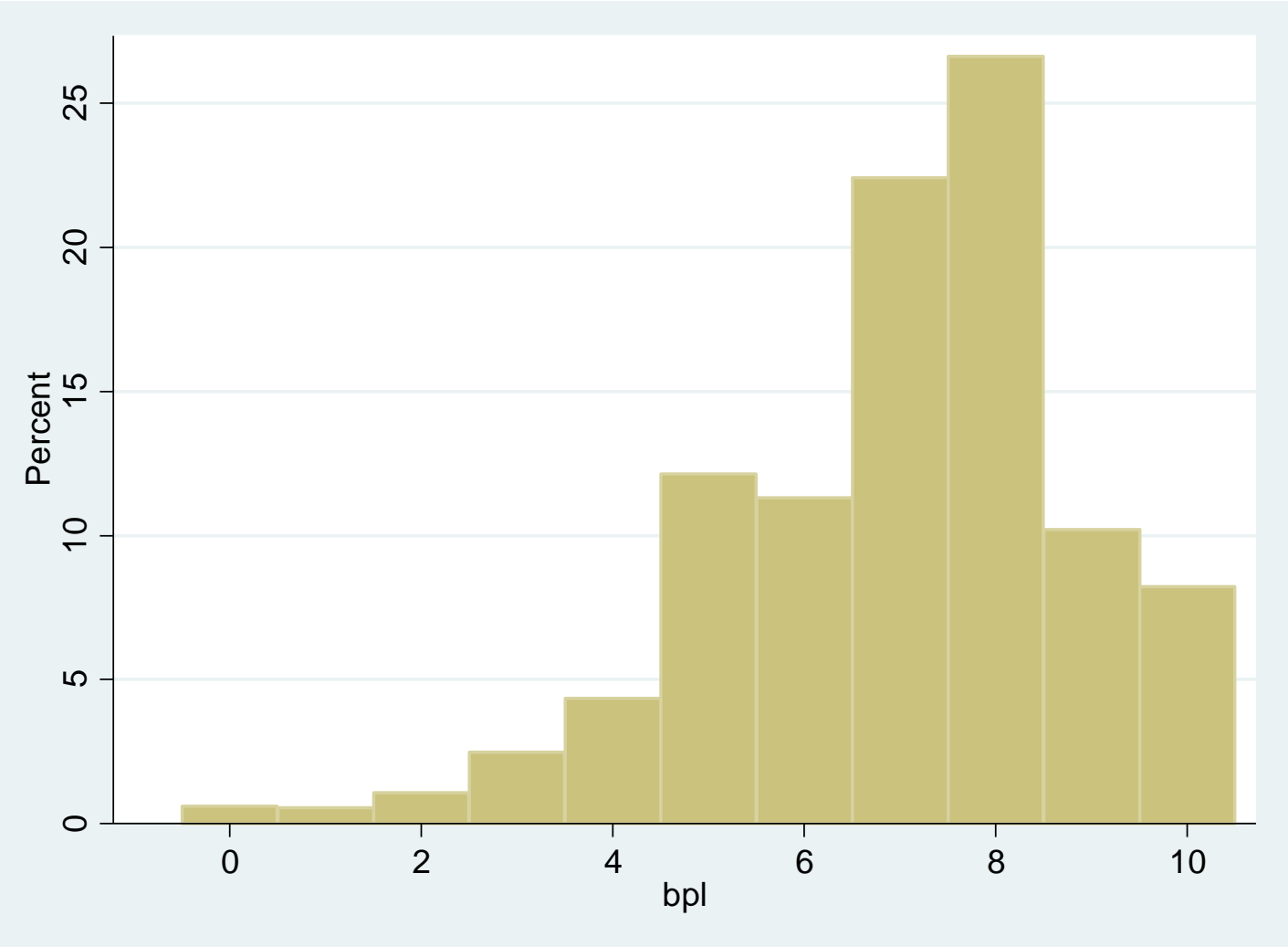


Table 1a: Summary statistics: Dependent variables

\begin{tabular}{lcc}
\hline & Mean & St. Dev. \\
\hline BPL & 7.00 & $(1.89)$ \\
Enjoyment yesterday & 0.89 & $(0.32)$ \\
Happiness yesterday & 0.86 & $(0.35)$ \\
Sadness yesterday & 0.17 & $(0.37)$ \\
Stress yesterday & 0.38 & $(0.49)$ \\
Worry yesterday & 0.30 & $(0.46)$ \\
Self-reported health & 3.55 & $(1.10)$ \\
Asthma & 0.11 & $(0.31)$ \\
Cancer & 0.10 & $(0.29)$ \\
Depression & 0.16 & $(0.37)$ \\
Diabetes & 0.12 & $(0.32)$ \\
Heart attack & 0.05 & $(0.21)$ \\
High blood pressure & 0.34 & $(0.47)$ \\
High cholesterol & 0.31 & $(0.46)$ \\
BMI & 27.29 & $(5.59)$ \\
Smoke & 0.16 & $(0.37)$ \\
Days last week with 30 min. exercise & 2.82 & $(2.40)$ \\
Days last week ate 5 fruits/veggies & 4.14 & $(2.53)$ \\
Satisfaction with city & 0.88 & $(0.33)$ \\
Observations & 456,719 \\
\hline
\end{tabular}

Notes: Standard deviations in parenthesis. BPL ranges from 0-10. Hedonic SWB, health markers, smoke, exercise, and satisfaction with city questions coded $1=$ "Yes," \& 0 = "No." Self-reported health coded $1=$ "Poor," $2=$

"Fair," 3 = "Good," 4 = "Very good," \& 5 = "Excellent." BMI ranges from 7.7137.3. 
Table 1b: Summary statistics: Independent variables

\begin{tabular}{lcc}
\hline & Mean & St. Dev. \\
\hline Female & 0.50 & $(0.50)$ \\
Asian & 0.03 & $(0.16)$ \\
Black & 0.10 & $(0.29)$ \\
Hispanic origin & 0.09 & $(0.28)$ \\
White & 0.84 & $(0.36)$ \\
Age & 52.79 & $(17.74)$ \\
Married & 0.54 & $(0.50)$ \\
Single & 0.19 & $(0.39)$ \\
Divorced & 0.11 & $(0.32)$ \\
Separated & 0.02 & $(0.14)$ \\
Widowed & 0.10 & $(0.30)$ \\
Domestic partner & 0.04 & $(0.19)$ \\
Did not complete high school & 0.05 & $(0.21)$ \\
High school graduate & 0.17 & $(0.38)$ \\
Technical degree & 0.07 & $(0.25)$ \\
Some college & 0.25 & $(0.43)$ \\
College degree & 0.25 & $(0.43)$ \\
Post graduate work or degree & 0.22 & $(0.41)$ \\
Children in household & 0.30 & $(0.46)$ \\
Employed in last 7 days & 0.51 & $(0.50)$ \\
Median annual household & & \\
income & $\$ 54,000$ & - \\
Median ZIP-code incomes & $\$ 61,200$ & $(\$ 23,325)$ \\
Median MSA incomes & $\$ 54,083$ & $(\$ 10,098)$ \\
Median MSA incomes $(5-y e a r) ~$ & $\$ 56,327$ & $(\$ 10,203)$ \\
Median ZIP-code rents & $\$ 973$ & $(\$ 308)$ \\
Median MSA rents & $\$ 910$ & $(\$ 203)$ \\
Median MSA rent $(5-y e a r)$ & $\$ 912$ & $(\$ 202)$ \\
ZIP-code Gini Coefficient & 0.43 & $(0.05)$ \\
MSA Gini Coefficient & 0.46 & $(0.02)$ \\
Observations & 456,719 \\
\hline & & \\
& & \\
& &
\end{tabular}


Table 2a: Neighbors' income and evaluative SWB

\begin{tabular}{lllll}
\hline & $\begin{array}{c}\text { BPL } \\
(1)\end{array}$ & $\begin{array}{c}\text { BPL } \\
(2)\end{array}$ & $\begin{array}{c}\text { BPL } \\
(3)\end{array}$ & $\begin{array}{c}\text { Sat. with City } \\
(4)\end{array}$ \\
\hline Ln ZIP-code median income & $0.076^{* * * * *}$ & & $0.062^{* * * *}$ & $0.125^{* * * * *}$ \\
& $(0.010)$ & & $(0.010)$ & $(0.003)$ \\
Ln MSA median income & & $-0.114^{* * * *}$ & $-0.173^{* * * *}$ & $-0.043^{* * * *}$ \\
& & $(0.024)$ & $(0.025)$ & $(0.007)$ \\
Ln own income & $0.334^{* * * *}$ & $0.337^{* * * *}$ & $0.335^{* * * *}$ & $0.018^{* * * *}$ \\
& $(0.005)$ & $(0.005)$ & $(0.005)$ & $(0.001)$ \\
Own income top coded & $0.279^{* * * *}$ & $0.284^{* * * *}$ & $0.279^{* * * *}$ & 0.001 \\
& $(0.008)$ & $(0.008)$ & $(0.008)$ & $(0.001)$ \\
Observations & 439,844 & 437,849 & 437,849 & 436,410 \\
\hline
\end{tabular}

Notes: Robust standard errors (clustered by ZIP-code) in parenthesis. Dependent variable in Columns (1) to (3) is BPL (range: $0-10 \&$ sample mean $=7.0$ ); dependent variable in Column (4) is satisfaction with city (coded $1=$ "Yes" \& $0=$ "No") . All models are estimated using OLS and condition on own income; gender; race; age; marital, parental, \& employment status; education; state; and day, month, \& year of interview. Column (1) also includes county and MSA fixed effects. **, ***,**** signify the coefficient is statistically significant at $\mathrm{p}<0.05,0.01,0.001$, respectively.

Table 2b: Neighbors' income and hedonic SWB

\begin{tabular}{lccccc}
\hline & Enjoyment & Happiness & Sadness & Stress & Worry \\
& $(1)$ & $(2)$ & $(3)$ & $(4)$ & $(5)$ \\
\hline Ln ZIP-code median income & $0.009^{* * * *}$ & $0.011^{* * * *}$ & $-0.010^{* * * *}$ & 0.003 & 0.000 \\
& $(0.002)$ & $(0.002)$ & $(0.002)$ & $(0.002)$ & $(0.002)$ \\
Ln MSA median income & $-0.031^{* * * *}$ & $-0.032^{* * * *}$ & $0.020^{* * * *}$ & $0.010^{*}$ & $0.030^{* * * *}$ \\
& $(0.005)$ & $(0.004)$ & $(0.005)$ & $(0.006)$ & $(0.006)$ \\
Ln own income & $0.034^{* * * *}$ & $0.031^{* * * *}$ & $-0.044^{* * * *}$ & $-0.042^{* * * *}$ & $-0.055^{* * * *}$ \\
& $(0.001)$ & $(0.001)^{* * *}$ & $(0.001)$ & $(0.001)$ & $\left.(0.001)^{*}\right)$ \\
Own income top coded & 0.001 & $-0.003^{* * *}$ & $0.008^{* * * *}$ & $0.023^{* * * *}$ & $0.007^{* * *}$ \\
& $(0.001)$ & $(0.001)$ & $(0.002)$ & $(0.002)$ & $(0.002)$ \\
Observations & 437,051 & $436,87)^{*}$ & 437,453 & 437,374 & 437,416 \\
\hline
\end{tabular}

Notes: Robust standard errors (clustered by ZIP-code) in parenthesis. Dependent variable indicate whether the emotion was felt yesterday (coded $1=$ "Yes" \& $0=$ "No"). All models are estimated using OLS and condition on own income; gender; race; age; marital, parental, \& employment status; education; state; and day, month, \& year of interview. **, ***, $* * * *$ signify the coefficient is statistically significant at $\mathrm{p}<0.05,0.01,0.001$, respectively. 
Table 3: Neighbors' income and various measures of well-being

\begin{tabular}{|c|c|c|c|c|c|c|c|c|}
\hline \multirow[b]{2}{*}{ Self-reported health } & \multicolumn{2}{|c|}{$\begin{array}{c}\text { ZIP-code } \\
\text { median } \\
\text { income } \\
(1)\end{array}$} & \multicolumn{2}{|c|}{$\begin{array}{c}\text { MSA } \\
\text { median } \\
\text { income } \\
(2)\end{array}$} & \multicolumn{2}{|c|}{$\begin{array}{c}\text { Own income } \\
\text { (3) }\end{array}$} & \multicolumn{2}{|c|}{$\begin{array}{c}\text { Own income } \\
\text { top coded } \\
(4)\end{array}$} \\
\hline & 0.172 & $* * * *$ & -0.055 & $* * * *$ & 0.147 & $* * * *$ & 0.103 & $* * * *$ \\
\hline \multicolumn{9}{|l|}{ Health markers } \\
\hline Asthma & -0.014 & $* * * *$ & 0.001 & & -0.011 & $* * * *$ & 0.003 & $*$ \\
\hline Cancer & 0.002 & & -0.004 & & 0.000 & & -0.005 & $* * * *$ \\
\hline Depression & -0.030 & $* * * *$ & 0.014 & $* * *$ & -0.037 & $* * * *$ & -0.005 & $* * *$ \\
\hline Diabetes & -0.029 & $* * * *$ & -0.009 & $*$ & -0.010 & $* * * *$ & -0.013 & **** \\
\hline Heart attack & -0.013 & $* * * *$ & -0.001 & & -0.007 & $* * * *$ & -0.002 & $* *$ \\
\hline High blood pressure & -0.031 & $* * * *$ & -0.017 & $* *$ & -0.009 & $* * * *$ & -0.023 & $* * * *$ \\
\hline High cholesterol & -0.004 & $*$ & -0.009 & & -0.004 & $* * * *$ & -0.007 & $* * * *$ \\
\hline \multicolumn{9}{|l|}{ Health behaviors } \\
\hline BMI & -0.681 & $* * * *$ & -0.717 & $* * * *$ & -0.125 & $* * * *$ & -0.534 & $* * * *$ \\
\hline Smoke & -0.042 & $* * * *$ & 0.000 & & -0.024 & $* * * *$ & -0.014 & $* * * *$ \\
\hline days@wk. exercise 30 min. & 0.047 & $* * * *$ & -0.157 & $* * * *$ & 0.039 & $* * * *$ & 0.143 & $* * * *$ \\
\hline days@wk. eat 5 fruit or veggies & -0.040 & $* * * *$ & -0.009 & & 0.041 & $* * * *$ & 0.029 & $* *$ \\
\hline
\end{tabular}

Notes: All models are estimated using OLS and condition on own income; gender; race; age; marital, parental, $\&$ employment status; education; state; and day, month, \& year of interview. *, **, ***, **** signify the coefficient is statistically significant at $\mathrm{p}<0.10,0.05,0.01,0.001$, respectively. Self-reported health coded $1=$ "Poor," 2 = "Fair," 3 = "Good," 4 = "Very good," \& 5 = "Excellent." Health markers, smoke, and exercise questions coded $1=$ "Yes," \& 0 = "No." BMI ranges from 7.7-137.3. 
Table 4a: Conditioning on channel-proxies, BPL

\begin{tabular}{|c|c|c|c|c|c|}
\hline & $\begin{array}{c}\text { No } \\
\text { channels } \\
\text { (1) }\end{array}$ & $\begin{array}{c}\text { Public-goods } \\
\text { channel } \\
\text { (2) }\end{array}$ & $\begin{array}{l}\text { Cost of living } \\
\text { channel } \\
\text { (3) }\end{array}$ & $\begin{array}{c}\text { Expectations } \\
\text { channel } \\
(4)\end{array}$ & $\begin{array}{c}\text { All } \\
\text { channels } \\
(5)\end{array}$ \\
\hline Ln ZIP-code median income & $\begin{array}{l}0.062^{* * * *} \\
(0.010)\end{array}$ & $\begin{array}{l}0.009 \\
(0.011)\end{array}$ & $\begin{array}{l}0.055^{* * * *} \\
(0.013)\end{array}$ & $\begin{array}{l}0.048^{* * * *} \\
(0.008)\end{array}$ & $\begin{array}{l}0.008 \\
(0.012)\end{array}$ \\
\hline Ln MSA median income & $\begin{array}{c}-0.173^{* * * *} \\
(0.025)\end{array}$ & $\begin{array}{c}-0.252^{* * * *} \\
(0.027)\end{array}$ & $\begin{array}{l}0.009 \\
(0.045)\end{array}$ & $\begin{array}{c}-0.194^{* * * *} \\
(0.022)\end{array}$ & $\begin{array}{r}-0.046 \\
(0.038)\end{array}$ \\
\hline Ln own income & $\begin{array}{l}0.335^{\text {***** }} \\
(0.005)\end{array}$ & $\begin{array}{l}0.335^{* * * *} \\
(0.005)\end{array}$ & $\begin{array}{l}0.334^{* * * *} \\
(0.005)\end{array}$ & $\begin{array}{l}0.239^{* * * *} \\
(0.004)\end{array}$ & $\begin{array}{l}0.239^{* * * *} \\
(0.004)\end{array}$ \\
\hline Own income top coded & $\begin{array}{l}0.279^{* * * *} \\
(0.008)\end{array}$ & $\begin{array}{l}0.277^{* * * *} \\
(0.008)\end{array}$ & $\begin{array}{l}0.280^{* * * *} \\
(0.008)\end{array}$ & $\begin{array}{l}0.179^{* * * *} \\
(0.007)\end{array}$ & $\begin{array}{l}0.179^{* * * *} \\
(0.007)\end{array}$ \\
\hline Mean ZIP-code BPL & & $\begin{array}{l}0.086^{* * * *} \\
(0.009)\end{array}$ & & & $\begin{array}{l}0.052^{* * * *} \\
(0.008)\end{array}$ \\
\hline Mean ZIP-code satisfaction w/ city & & $\begin{array}{l}0.151^{* * * *} \\
(0.039)\end{array}$ & & & $\begin{array}{l}0.215^{* * * *} \\
(0.034)\end{array}$ \\
\hline Median ZIP-code rent & & & $\begin{array}{l}0.013 \\
(0.021)\end{array}$ & & $\begin{array}{c}-0.023 \\
(0.017)\end{array}$ \\
\hline Mean MSA BPL & & $\begin{array}{l}0.323^{* * * *} \\
(0.037)\end{array}$ & & & $\begin{array}{l}0.232^{* * * *} \\
(0.033)\end{array}$ \\
\hline Mean MSA satisfaction w/ city & & $\begin{array}{l}0.104 \\
(0.110)\end{array}$ & & & $\begin{array}{c}-0.016 \\
(0.103)\end{array}$ \\
\hline Median MSA rent & & & $\begin{array}{c}-0.233^{* * * *} \\
(0.049)\end{array}$ & & $\begin{array}{c}-0.228^{* * * *} \\
(0.039)\end{array}$ \\
\hline BPL in 5 years & & & & $\begin{array}{l}0.457^{* * * *} \\
(0.002)\end{array}$ & $\begin{array}{l}0.457^{* * * *} \\
(0.002)\end{array}$ \\
\hline Observations & 437,849 & 437,166 & 436,414 & 420,909 & 419,103 \\
\hline
\end{tabular}

Notes: Robust standard errors (clustered by ZIP code) in parenthesis. Dependent variable is BPL (range: 0 -10 \& sample mean $=7.0$ ). All models are estimated using OLS and condition on own income; gender; race; age; marital, parental, \& employment status; education; state; and day, month, \& year of interview. Columns (3) \& (5) also include an indicator variables for median ZIP-code rent being top- and bottom-coded (no median MSA rents are top- or bottom-coded). Median MSA rent is in thousands of dollars. $* *, * * *, * * *$ signify the coefficient is statistically significant at $\mathrm{p}<$ $0.05,0.01,0.001$, respectively. 
Table 4b: Conditioning on channel-proxies, hedonic SWB

\begin{tabular}{|c|c|c|c|c|c|}
\hline & $\begin{array}{c}\text { Enjoyment } \\
\text { (1) }\end{array}$ & $\begin{array}{c}\text { Happiness } \\
\text { (2) }\end{array}$ & $\begin{array}{c}\text { Sadness } \\
\text { (3) }\end{array}$ & $\begin{array}{l}\text { Stress } \\
(4)\end{array}$ & $\begin{array}{l}\text { Worry } \\
(5)\end{array}$ \\
\hline Ln ZIP-code median income & $\begin{array}{l}0.009^{* * * *} \\
(0.003)\end{array}$ & $\begin{array}{l}0.012^{* * * *} \\
(0.002)\end{array}$ & $\begin{array}{c}-0.009^{* * *} \\
(0.003)\end{array}$ & $\begin{array}{c}-0.008^{* *} \\
(0.004)\end{array}$ & $\begin{array}{l}-0.013^{* * * *} \\
(0.004)\end{array}$ \\
\hline Ln MSA median income & $\begin{array}{c}-0.006 \\
(0.009)\end{array}$ & $\begin{array}{l}-0.011 \\
(0.008)\end{array}$ & $\begin{array}{c}-0.031^{* * * *} \\
(0.009)\end{array}$ & $\begin{array}{c}-0.035^{* * *} \\
(0.012)\end{array}$ & $\begin{array}{c}-0.055^{* * * *} \\
(0.011)\end{array}$ \\
\hline Ln own income & $\begin{array}{l}0.028^{* * * *} \\
(0.001)\end{array}$ & $\begin{array}{l}0.025^{* * * *} \\
(0.001)\end{array}$ & $\begin{array}{c}-0.038^{* * * *} \\
(0.001)\end{array}$ & $\begin{array}{c}-0.036^{* * * *} \\
(0.001)\end{array}$ & $\begin{array}{l}-0.048^{* * * *} \\
(0.001)\end{array}$ \\
\hline Own income top coded & $\begin{array}{c}-0.004^{* * *} \\
(0.001)\end{array}$ & $\begin{array}{c}-0.008^{* * * *} \\
(0.001)\end{array}$ & $\begin{array}{l}0.013^{* * * *} \\
(0.002)\end{array}$ & $\begin{array}{l}0.028^{* * * *} \\
(0.002)\end{array}$ & $\begin{array}{l}0.012^{* * * *} \\
(0.002)\end{array}$ \\
\hline Mean ZIP-code BPL & $\begin{array}{l}0.003 * \\
(0.001)\end{array}$ & $\begin{array}{l}0.001 \\
(0.001)\end{array}$ & $\begin{array}{l}0.001 \\
(0.002)\end{array}$ & $\begin{array}{c}-0.001 \\
(0.002)\end{array}$ & $\begin{array}{l}0.003 \\
(0.002)\end{array}$ \\
\hline Mean ZIP-code satisfaction w/ city & $\begin{array}{l}0.015^{*} \\
(0.008)\end{array}$ & $\begin{array}{l}0.012 * \\
(0.007)\end{array}$ & $\begin{array}{l}-0.002 \\
(0.008)\end{array}$ & $\begin{array}{l}0.032^{* * *} \\
(0.011)\end{array}$ & $\begin{array}{l}0.021^{* *} \\
(0.010)\end{array}$ \\
\hline Median ZIP-code rent & $\begin{array}{c}-0.009^{* *} \\
(0.004)\end{array}$ & $\begin{array}{c}-0.010^{* * *} \\
(0.003)\end{array}$ & $\begin{array}{l}-0.003 \\
(0.004)\end{array}$ & $\begin{array}{l}0.013^{* *} \\
(0.005)\end{array}$ & $\begin{array}{l}0.017^{* * *} \\
(0.005)\end{array}$ \\
\hline Mean MSA BPL & $\begin{array}{l}0.019^{* *} \\
(0.007)\end{array}$ & $\begin{array}{l}0.009 \\
(0.006)\end{array}$ & $\begin{array}{c}-0.017^{* *} \\
(0.008)\end{array}$ & $\begin{array}{c}-0.025^{* *} \\
(0.010)\end{array}$ & $\begin{array}{l}-0.026^{* * *} \\
(0.010)\end{array}$ \\
\hline Mean MSA satisfaction w/ city & $\begin{array}{l}0.072^{* * *} \\
(0.023)\end{array}$ & $\begin{array}{l}0.061^{* * *} \\
(0.020)\end{array}$ & $\begin{array}{c}-0.019 \\
(0.024)\end{array}$ & $\begin{array}{r}-0.038 \\
(0.032)\end{array}$ & $\begin{array}{c}-0.007 \\
(0.031)\end{array}$ \\
\hline Median MSA rent & $\begin{array}{c}-0.041^{* * * *} \\
(0.009)\end{array}$ & $\begin{array}{c}-0.031^{* * * *} \\
(0.008)\end{array}$ & $\begin{array}{l}0.073^{* * * *} \\
(0.009)\end{array}$ & $\begin{array}{l}0.068^{* * * *} \\
(0.012)\end{array}$ & $\begin{array}{l}0.113^{* * * *} \\
(0.012)\end{array}$ \\
\hline $\mathrm{BPL}$ in 5 years & $\begin{array}{l}0.028^{* * * *} \\
(0.000)\end{array}$ & $\begin{array}{l}0.025^{* * * *} \\
(0.000)\end{array}$ & $\begin{array}{c}-0.024^{* * * *} \\
(0.000)\end{array}$ & $\begin{array}{c}-0.031^{* * * *} \\
(0.000)\end{array}$ & $\begin{array}{l}-0.034^{* * * *} \\
(0.000)\end{array}$ \\
\hline Observations & 418,499 & 418,371 & 418,803 & 418,732 & 418,760 \\
\hline \multicolumn{6}{|c|}{$\begin{array}{l}\text { Notes: Robust standard errors (clustered by ZIP-code) in parenthesis. Dependent variable indicate whether the } \\
\text { emotion was felt yesterday (coded } 1=\text { "Yes" \& } 0=\text { "No"). All models are estimated using OLS and condituon on } \\
\text { own income; gender; race; age; marital, parental, \& employment status; education; state; day, month, \& year of } \\
\text { interview; and whether median ZIP-code rent being top- and bottom-coded (no median MSA rents are top- or } \\
\text { bottom-coded). }{ }^{* *},{ }^{* *},{ }^{* * *} \text { signify the coefficient is statistically significant at } \mathrm{p}<0.05,0.01,0.001 \text {, } \\
\text { respectively. }\end{array}$} \\
\hline
\end{tabular}


Table 5: Estimates by income-subgroups

\begin{tabular}{|c|c|c|c|c|}
\hline & $\begin{array}{l}\text { Median } \\
\text { income } \\
(1)\end{array}$ & $\begin{array}{l}\text { Ln ZIP-code } \\
\text { median } \\
\text { income } \\
(2)\end{array}$ & $\begin{array}{l}\text { Ln MSA } \\
\text { median } \\
\text { income } \\
(3)\end{array}$ & $\begin{array}{l}\text { Ln own } \\
\text { income } \\
(4)\end{array}$ \\
\hline \multicolumn{5}{|c|}{ Panel A: Income-group interactions } \\
\hline LL respondents & $\$ 18,000$ & $\begin{array}{l}-0.203^{* * * *} \\
(0.039)\end{array}$ & $\begin{array}{l}0.289^{* * * *} \\
(0.053)\end{array}$ & $\begin{array}{l}0.209^{* * * *} \\
(0.009)^{4}\end{array}$ \\
\hline LH respondents & $\$ 42,000$ & $\begin{array}{l}0.323^{* * * * *} \\
(0.026)^{2}\end{array}$ & $\begin{array}{c}-0.277^{* * * * *} \\
(0.040)\end{array}$ & $\begin{array}{l}0.278^{* * * * *} \\
(0.007)\end{array}$ \\
\hline HL respondents & $\$ 75,000$ & $\begin{array}{l}0.070^{* *} \\
(0.030)\end{array}$ & $\begin{array}{c}-0.256^{* * * * *} \\
(0.043)\end{array}$ & $\begin{array}{l}0.480^{* * * *} \\
(0.022)\end{array}$ \\
\hline $\mathrm{HH}$ respondents & $\$ 105,000$ & $\begin{array}{l}0.096^{* * *} \\
(0.029)\end{array}$ & $\begin{array}{l}-0.315^{* * * *} \\
(0.040)\end{array}$ & $\begin{array}{l}0.529^{* * * *} \\
(0.030)\end{array}$ \\
\hline \multicolumn{5}{|c|}{ Panel B: Subgroups (channel-proxies incl.) } \\
\hline LL respondents & $\$ 18,000$ & $\begin{array}{l}-0.169^{* * * *} \\
(0.042)\end{array}$ & $\begin{array}{l}-0.003 \\
(0.115)\end{array}$ & $\begin{array}{l}0.169^{* * * *} \\
(0.009)\end{array}$ \\
\hline Non-LL respondents & $\$ 75,000$ & $\begin{array}{l}0.014 \\
(0.012)\end{array}$ & $\begin{array}{l}0.009 \\
(0.039)\end{array}$ & $\begin{array}{l}0.254^{* * * *} \\
(0.005)\end{array}$ \\
\hline
\end{tabular}

Notes: Robust standard errors (clustered by ZIP-code) in parenthesis. Dependent variable is BPL (range: 0-10 \& sample mean =7.0). All models are estimated using OLS; and condition on own income; gender; race; age; marital, parental, \& employment status; education; state; and day, month, \& year of interview. Panel A includes interaction terms for ZIP-code median income, MSA median income, own income, and own income top-coded. Panel B coefficients are estimated with the sample restricted LL respondents and non-LL respondents and conditioning on all channel-proxies. $* *, * * *, * * * *$ signify the coefficient is statistically significant at $\mathrm{p}<0.05,0.01,0.001$, respectively. 
Table 6: Estimates by subgroup

\begin{tabular}{|c|c|c|c|}
\hline & $\begin{array}{l}\text { Ln ZIP-code } \\
\text { median } \\
\text { income } \\
(1)\end{array}$ & $\begin{array}{c}\text { Ln MSA } \\
\text { median income } \\
(2)\end{array}$ & $\begin{array}{l}\text { Ln own } \\
\text { income } \\
(3)\end{array}$ \\
\hline \multicolumn{4}{|l|}{ Panel A: Marital status } \\
\hline Unmarried $^{\wedge}$ & $\begin{array}{c}0.018 \\
(0.014)\end{array}$ & $\begin{array}{l}-0.092^{* * *} \\
(0.033)\end{array}$ & $\begin{array}{l}0.303^{* * * *} \\
(0.006)\end{array}$ \\
\hline Married & $\begin{array}{l}0.100^{* * * *} \\
(0.013)^{*}\end{array}$ & $\begin{array}{l}-0.251^{* * * * *} \\
(0.029)\end{array}$ & $\begin{array}{l}0.420^{* * * *} \\
(0.008)\end{array}$ \\
\hline p-value on test of equality (two estimates above) & $\{0.000\}$ & $\{0.000\}$ & $\{0.000\}$ \\
\hline \multicolumn{4}{|l|}{ Panel B: Race } \\
\hline Non-white & $\begin{array}{l}-0.020 \\
(0.021)\end{array}$ & $\begin{array}{l}-0.270^{* * * * *} \\
(0.045)\end{array}$ & $\begin{array}{l}0.208^{* * * * *} \\
(0.009)\end{array}$ \\
\hline White & $\begin{array}{l}0.095^{* * * *} \\
(0.011)\end{array}$ & $\begin{array}{l}-0.183^{* * * *} \\
(0.027)\end{array}$ & $\begin{array}{l}0.374^{* * * *} \\
(0.005)\end{array}$ \\
\hline p-value on test of equality (two estimates above) & $\{0.000\}$ & $\{0.065\}$ & $\{0.000\}$ \\
\hline \multicolumn{4}{|l|}{ Panel C: Education } \\
\hline High school or less & $\begin{array}{l}-0.061^{* *} \\
(0.024)\end{array}$ & $\begin{array}{l}-0.019 \\
(0.048)\end{array}$ & $\begin{array}{l}0.286^{* * * *} \\
(0.009)\end{array}$ \\
\hline More than high school & $\begin{array}{l}0.094^{* * * *} \\
(0.010)\end{array}$ & $\begin{array}{l}-0.223^{* * * *} \\
(0.026)\end{array}$ & $\begin{array}{l}0.359^{* * * *} \\
(0.005)\end{array}$ \\
\hline p-value on test of equality (two estimates above) & $\{0.000\}$ & $\{0.000\}$ & $\{0.000\}$ \\
\hline \multicolumn{4}{|l|}{ Panel D: Employment } \\
\hline Not employed & $\begin{array}{l}0.086^{* * * *} \\
(0.015)\end{array}$ & $\begin{array}{l}-0.127^{* * * *} \\
(0.033)\end{array}$ & $\begin{array}{l}0.327^{* * * *} \\
(0.006)\end{array}$ \\
\hline Employed & $\begin{array}{l}0.037^{\text {**** }} \\
(0.012)\end{array}$ & $\begin{array}{l}-0.218^{* * * *} \\
(0.028)\end{array}$ & $\begin{array}{l}0.353^{* * * *} \\
(0.007)\end{array}$ \\
\hline p-value on test of equality (two estimates above) & $\{0.007\}$ & $\{0.009\}$ & $\{0.003\}$ \\
\hline \multicolumn{4}{|l|}{ Panel E: Gender } \\
\hline Female & $\begin{array}{l}0.072^{* * * *} \\
(0.014)^{*}\end{array}$ & $\begin{array}{l}-0.215^{* * * * *} \\
(0.032)\end{array}$ & $\begin{array}{l}0.339^{* * * * *} \\
(0.006)\end{array}$ \\
\hline Male & $\begin{array}{l}0.051^{* * * *} \\
(0.013)^{*}\end{array}$ & $\begin{array}{l}-0.130^{* * * *} \\
(0.031)\end{array}$ & $\begin{array}{l}0.332^{* * * *} \\
(0.006)\end{array}$ \\
\hline p-value on test of equality (two estimates above) & $\{0.242\}$ & $\{0.018\}$ & $\{0.419\}$ \\
\hline \multicolumn{4}{|l|}{ Panel F: Child(ren) } \\
\hline Child(ren) reside in household & $\begin{array}{l}0.073^{* * * *} \\
(0.017)\end{array}$ & $\begin{array}{l}-0.199^{* * * *} \\
(0.037)\end{array}$ & $\begin{array}{l}0.311^{* * * *} \\
(0.008)\end{array}$ \\
\hline Child(ren) does not reside in household & $\begin{array}{l}0.056^{* * * *} \\
(0.012)\end{array}$ & $\begin{array}{l}-0.162^{* * * *} \\
(0.028)\end{array}$ & $\begin{array}{l}0.344^{* * * *} \\
(0.005)\end{array}$ \\
\hline p-value on test of equality (two estimates above) & $\{0.380\}$ & $\{0.320\}$ & $\{0.000\}$ \\
\hline \multicolumn{4}{|l|}{ Panel G: Age (median age $=55)$} \\
\hline Less than median & $\begin{array}{l}0.074^{* * * *} \\
(0.013)\end{array}$ & $\begin{array}{l}-0.171^{* * * *} \\
(0.030)\end{array}$ & $\begin{array}{l}0.289^{* * * *} \\
(0.006)\end{array}$ \\
\hline Equal to or greater than median & $\begin{array}{l}0.045^{* * *} \\
(0.014)^{* *}\end{array}$ & $\begin{array}{l}-0.166^{* * * * *} \\
(0.032)\end{array}$ & $\begin{array}{l}0.406^{* * * *} \\
(0.007)\end{array}$ \\
\hline p-value on test of equality (two estimates above) & $\{0.119\}$ & $\{0.895\}$ & $\{0.000\}$ \\
\hline
\end{tabular}


Notes: Robust standard errors (clustered by ZIP-code) in parenthesis. Dependent variable is BPL (range: 0$10 \&$ sample mean =7.0). All models are estimated using OLS; condition on own income; gender; race; age; marital, parental, \& employment status; education; state; and day, month, \& year of interview; and include interaction terms for ZIP-code median income, MSA median income, own income, and own income top-coded. ${ }^{\wedge}$ Unmarried includes respondents who report being divorced, domestic partners, never married, separated, or widowed. $* *, * * *, * * * *$ signify the coefficient is statistically significant at $\mathrm{p}<0.05$, $0.01,0.001$, respectively. 
Table 7: Specification checks

\begin{tabular}{|c|c|c|c|c|c|c|c|c|}
\hline & $\begin{array}{l}\text { All } \\
(1)\end{array}$ & $\begin{array}{c}\text { Use county } \\
\text { (not MSA) } \\
\text { median income } \\
\text { (2) }\end{array}$ & $\begin{array}{c}\text { ZIP-code, } \\
\text { country, \& MSA } \\
\text { median income } \\
(3)\end{array}$ & $\begin{array}{c}\text { Median income } \\
\text { calculated from } \\
\text { Gallup data } \\
\text { (4) }\end{array}$ & $\begin{array}{c}\text { Use 5-year } \\
\text { estimate of MSA } \\
\text { median income } \\
\text { (5) }\end{array}$ & $\begin{array}{c}\text { Include ZIP- } \\
\text { code and MSA } \\
\text { GINI } \\
(6)\end{array}$ & $\begin{array}{l}\geq 30 \\
\text { respondents in } \\
\text { ZIP-code } \\
(7)\end{array}$ & $\begin{array}{c}\geq 60 \\
\text { respondents in } \\
\text { ZIP-code } \\
(8)\end{array}$ \\
\hline Ln ZIP-code median income & $\begin{array}{l}0.062^{* * * *} \\
(0.010)\end{array}$ & $\begin{array}{l}0.065^{* * * *} \\
(0.011)\end{array}$ & $\begin{array}{l}0.068^{\text {**** }} \\
(0.011)\end{array}$ & $\begin{array}{l}0.074^{* * * *} \\
(0.009)\end{array}$ & $\begin{array}{l}0.069^{* * * *} \\
(0.010)\end{array}$ & $\begin{array}{l}0.114^{* * * *} \\
(0.010)\end{array}$ & $\begin{array}{l}0.073^{* * * *} \\
(0.011)\end{array}$ & $\begin{array}{l}0.077^{* * * *} \\
(0.016)\end{array}$ \\
\hline Ln MSA median income & $\begin{array}{c}-0.173^{* * * *} \\
(0.025)\end{array}$ & & $\begin{array}{c}-0.141^{* * * *} \\
(0.037)\end{array}$ & $\begin{array}{c}-0.154^{* * * *} \\
(0.021)\end{array}$ & $\begin{array}{c}-0.206^{* * * *} \\
(0.026)\end{array}$ & $\begin{array}{c}-0.168^{* * * *} \\
(0.025)\end{array}$ & $\begin{array}{c}-0.162^{* * * *} \\
(0.029)\end{array}$ & $\begin{array}{c}-0.141^{* * * *} \\
(0.036)\end{array}$ \\
\hline Ln county median income & & $\begin{array}{c}-0.097^{* * * *} \\
(0.019)\end{array}$ & $\begin{array}{c}-0.037 \\
(0.024)\end{array}$ & & & & & \\
\hline Ln own income & $\begin{array}{l}0.335^{* * * *} \\
(0.005)\end{array}$ & $\begin{array}{l}0.329^{* * * * *} \\
(0.005)\end{array}$ & $\begin{array}{l}0.330^{* * * * *} \\
(0.005)\end{array}$ & $\begin{array}{l}0.334^{* * * *} \\
(0.005)\end{array}$ & $\begin{array}{l}0.331^{* * * * *} \\
(0.005)\end{array}$ & $\begin{array}{l}0.336^{* * * *} \\
(0.005)\end{array}$ & $\begin{array}{l}0.326^{* * * *} \\
(0.005)\end{array}$ & $\begin{array}{l}0.329^{* * * *} \\
(0.007)\end{array}$ \\
\hline Own income top coded & $\begin{array}{l}0.279^{* * * *} \\
(0.008)\end{array}$ & $\begin{array}{l}0.283^{* * * *} \\
(0.008)\end{array}$ & $\begin{array}{l}0.284^{* * * *} \\
(0.008)\end{array}$ & $\begin{array}{l}0.279^{* * * *} \\
(0.008)\end{array}$ & $\begin{array}{l}0.277^{* * * *} \\
(0.008)\end{array}$ & $\begin{array}{l}0.266^{* * * *} \\
(0.008)\end{array}$ & $\begin{array}{l}0.289^{* * * *} \\
(0.008)\end{array}$ & $\begin{array}{l}0.291^{* * * *} \\
(0.010)\end{array}$ \\
\hline Observations & 437,849 & 415,929 & 414,058 & 438,904 & 427,165 & 437,848 & 359,069 & 232,188 \\
\hline
\end{tabular}

